\title{
A transient phreatic surface mound, evidenced by a strip of vegetation in an earth dam shoulder
}

Kacimov Anvar and Brown Gary supplementary material submitted to HSJ 


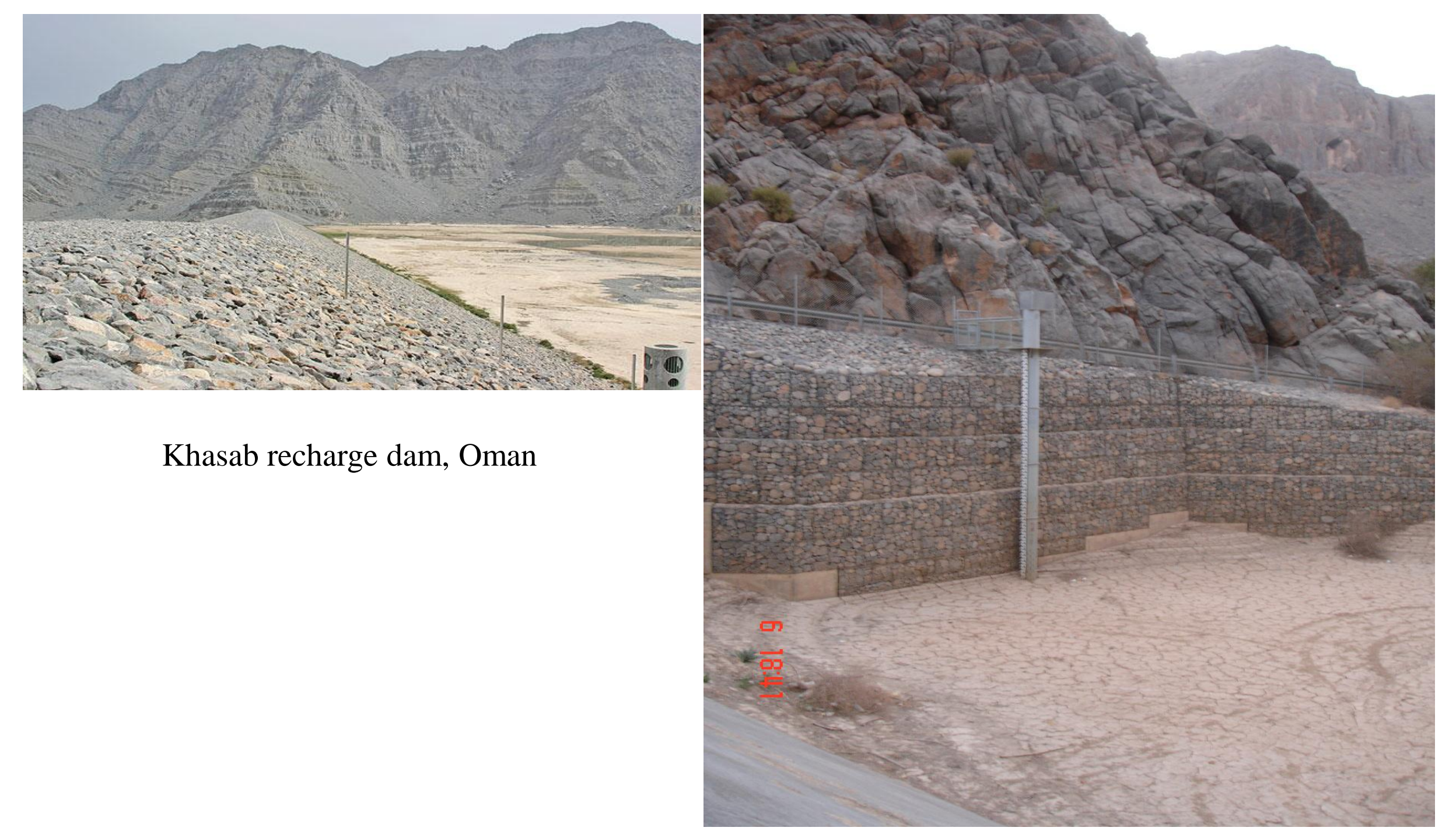

Tanuf recharge dam, Oman 


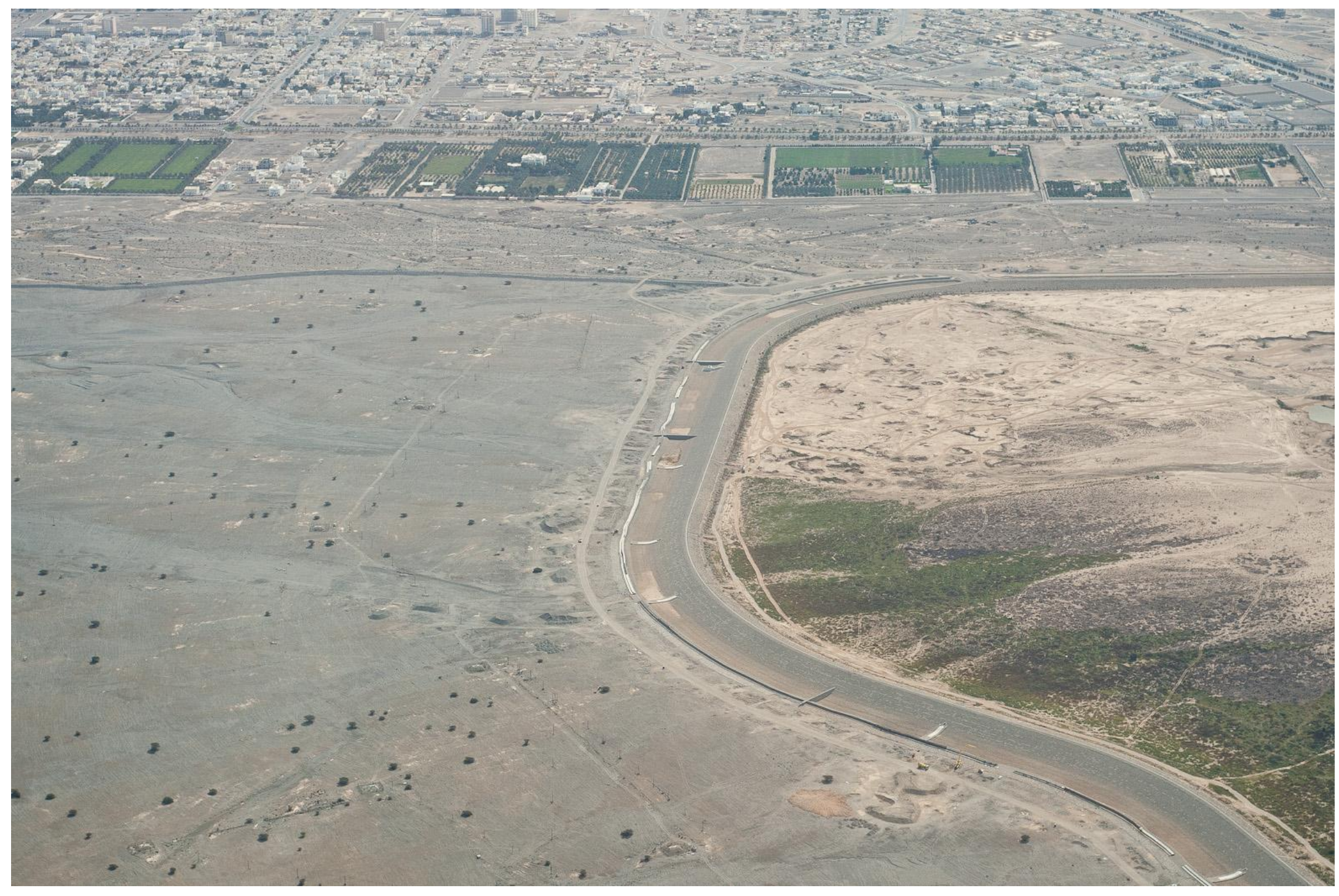

Aerial view of the Al-Khod dam 


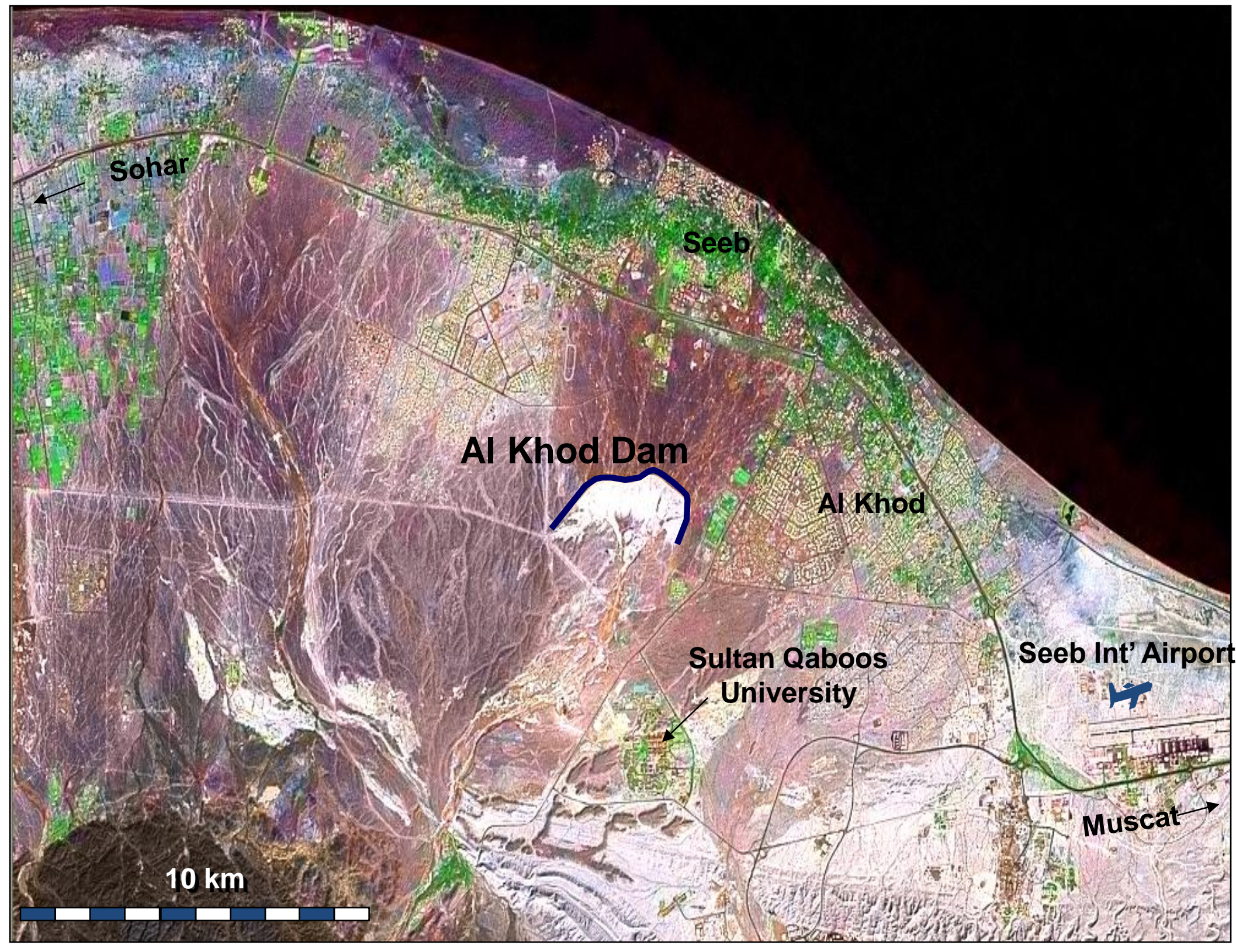

Satellite image of the Al-Khod dam. 

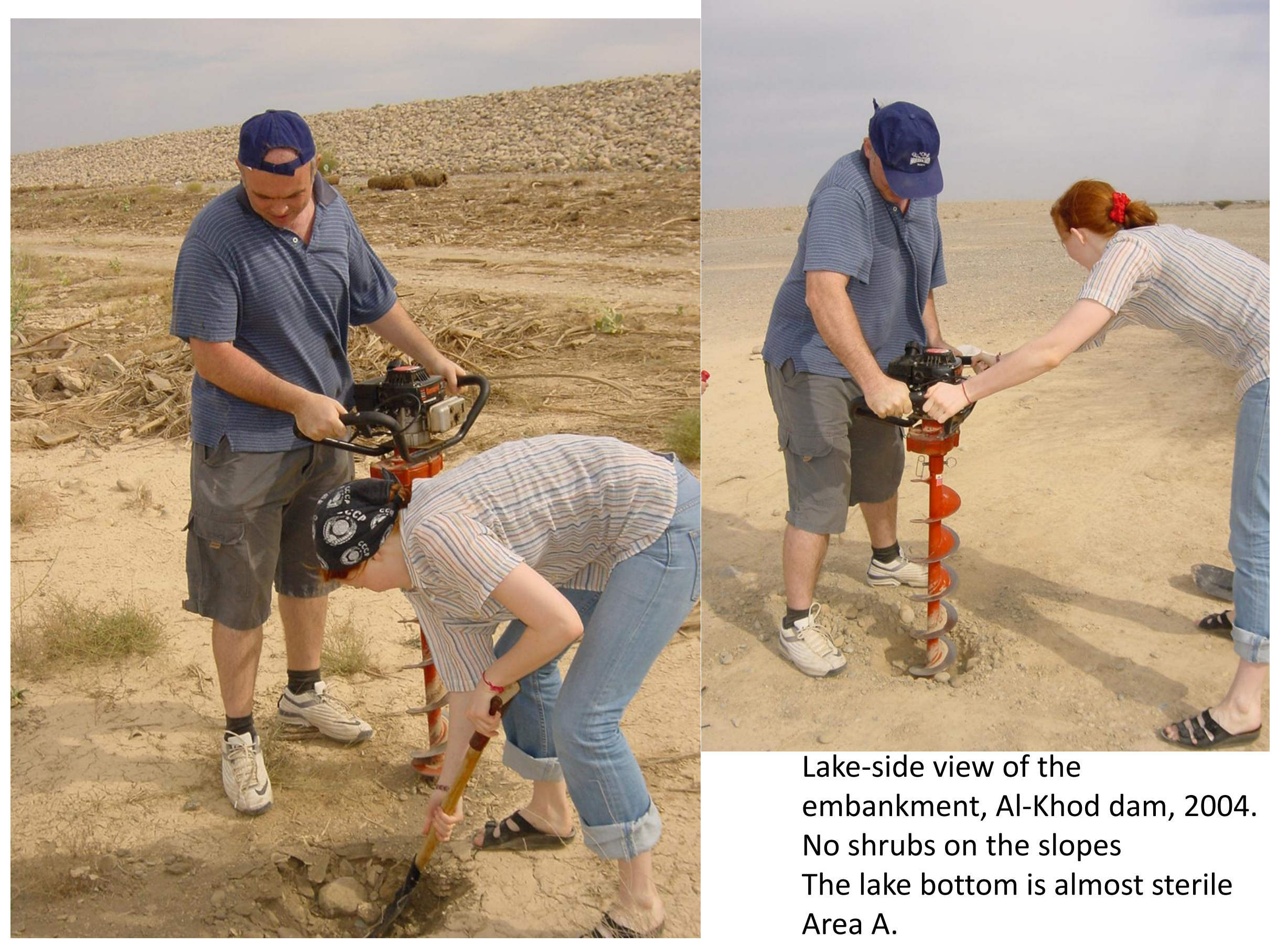

Lake-side view of the embankment, Al-Khod dam, 2004. No shrubs on the slopes The lake bottom is almost sterile Area A. 


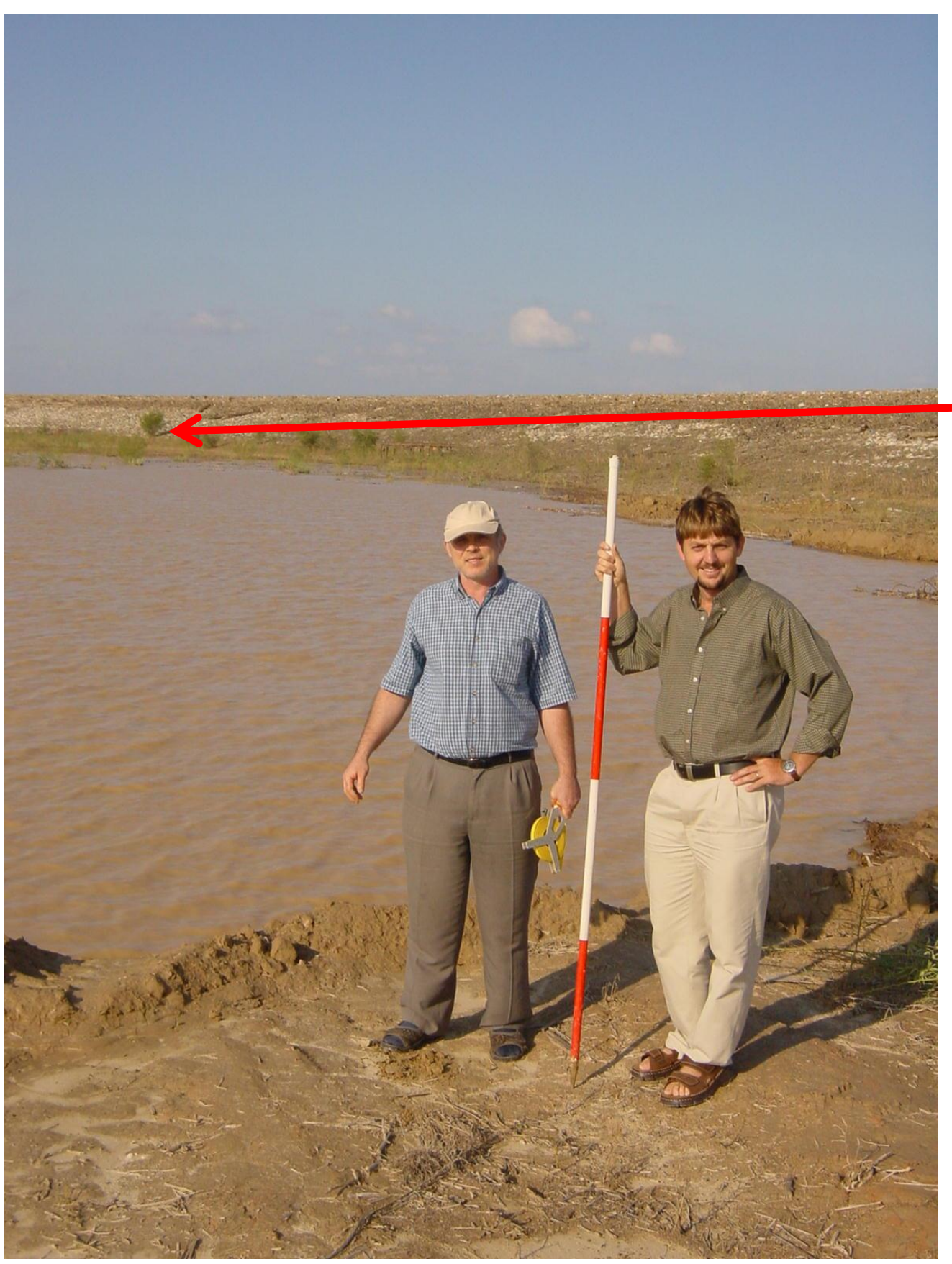

Wet season of 2005. The lake is partially filled. Levee slope vegetation emerging. Area $A$ 
Off-lake vegetation:

Acacia tortilis

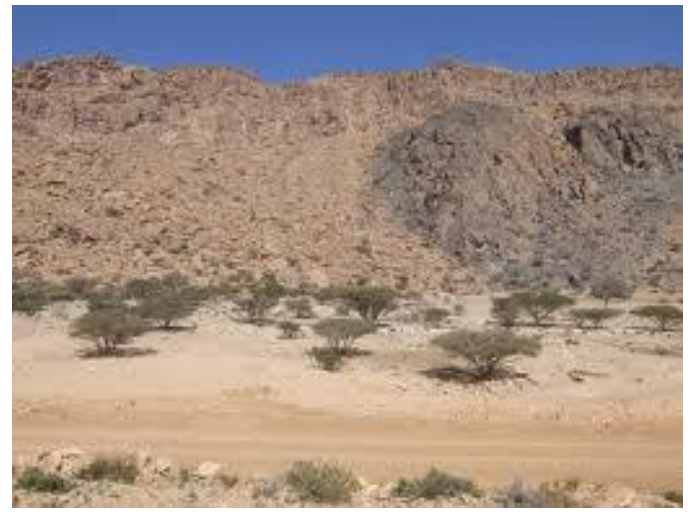

Euphorbia larica

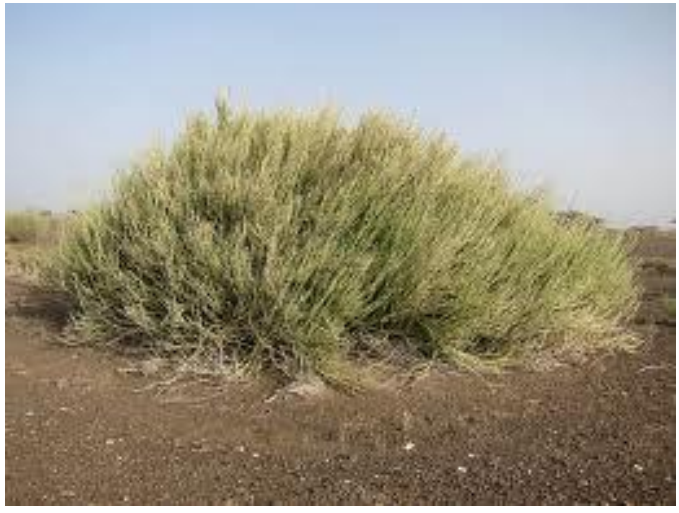

Crotalaria aegyptiaca
In-lake vegetation:

Parkinsonia aculeata

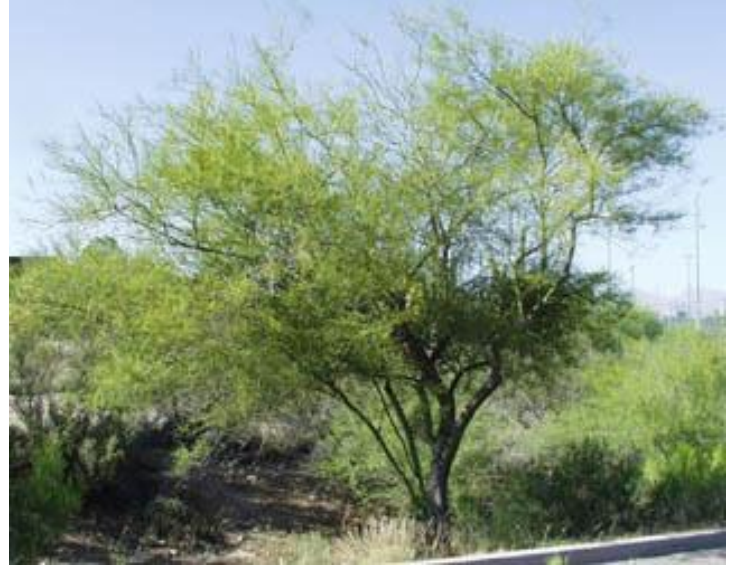

Prosopis juliflora

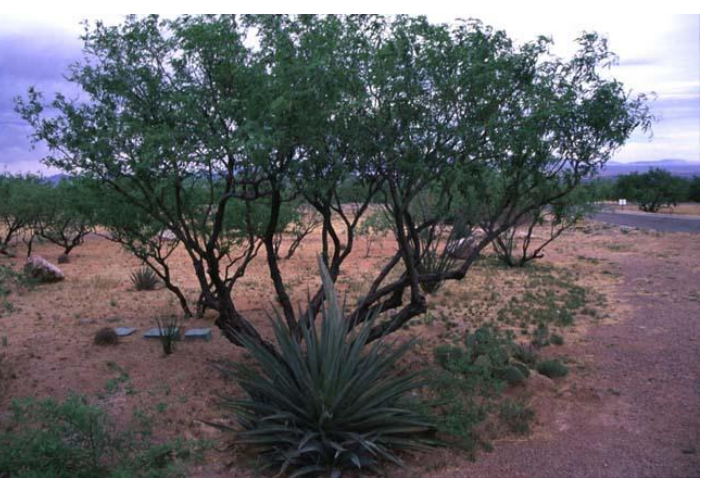

Ricinus communis

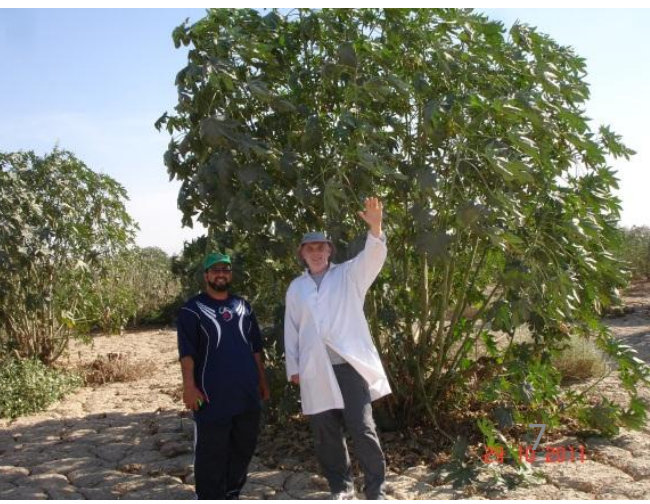

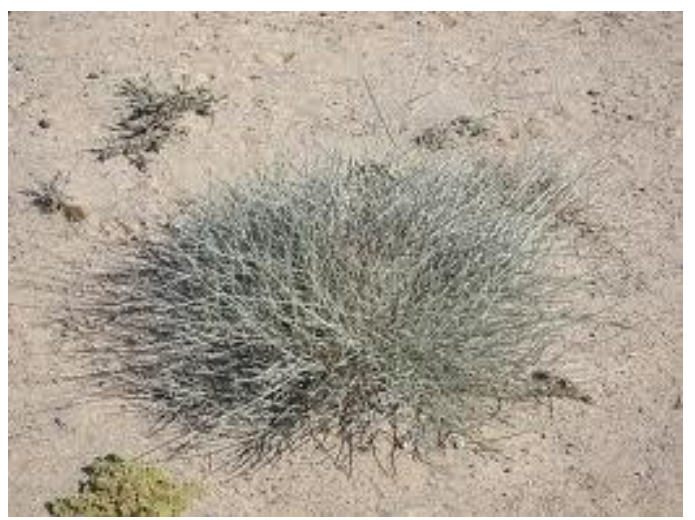




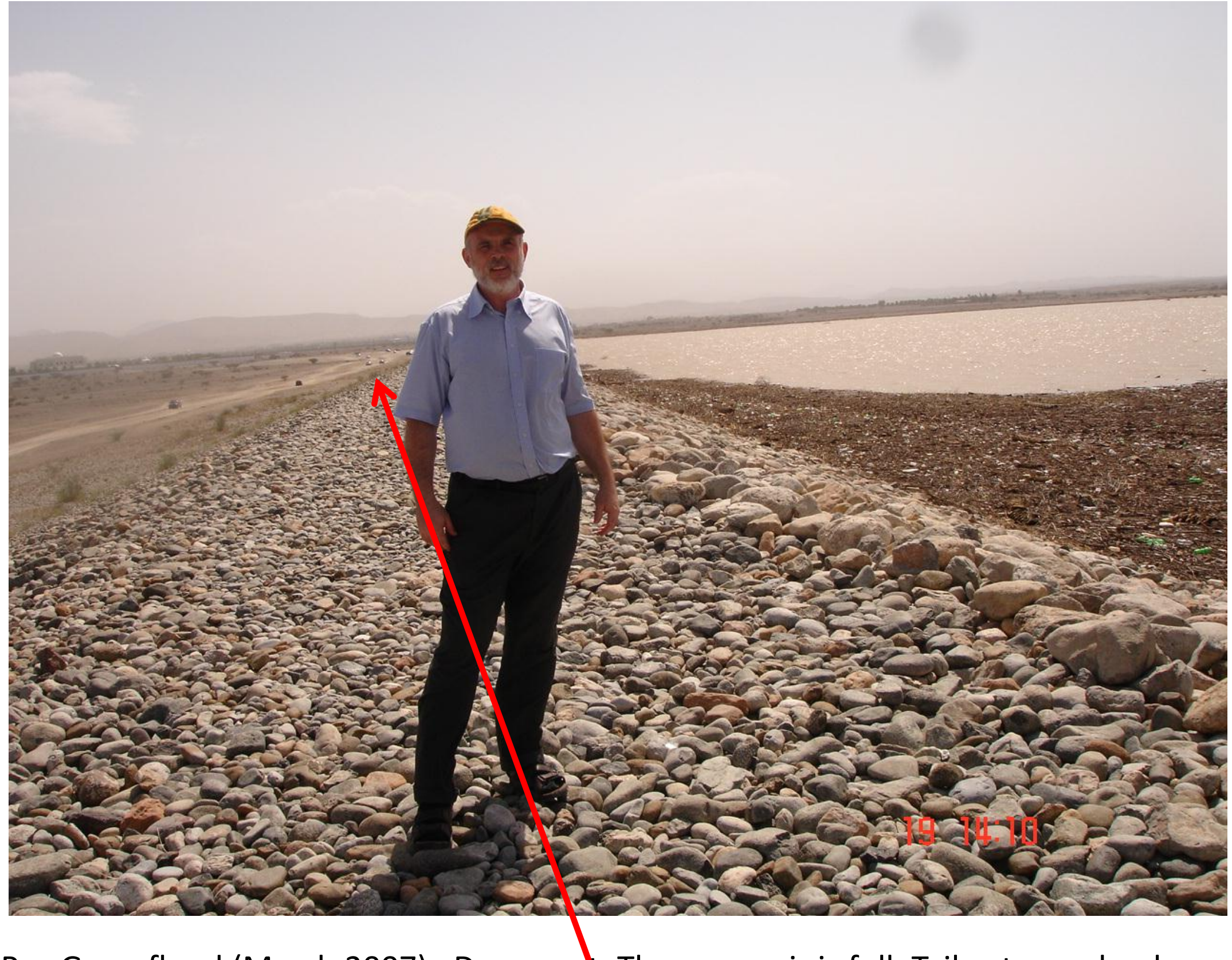

Pre-Gonu flood (March 2007). Dam cres. The reservoir is full. Tailwater embankment slope hosts occasional herbaceous species. Al-Khod dam. Area A 



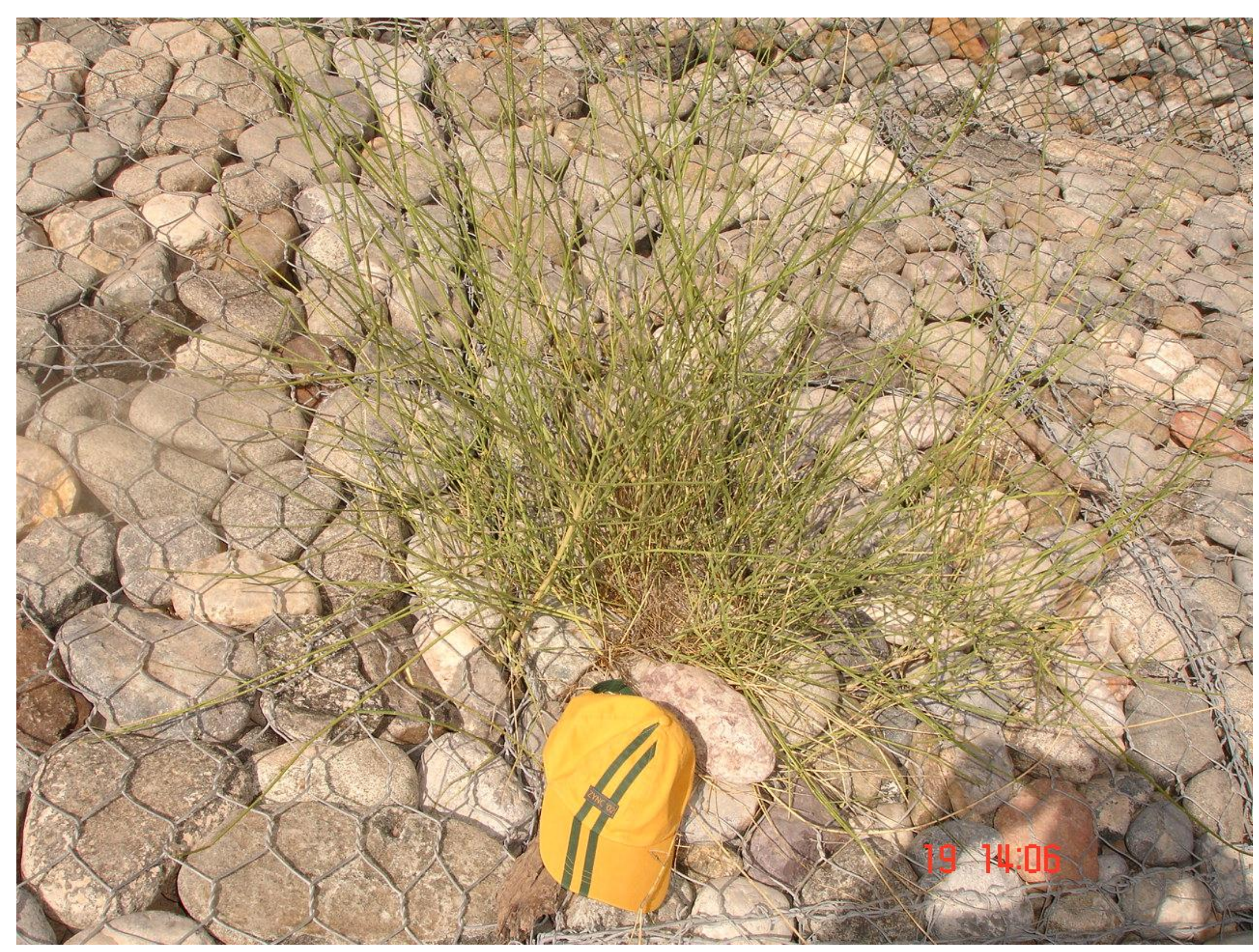

March 2007. Tailwater side of the levee. Plant growing through rip-rap on the gabion. Al-Khod dam. Area A. 


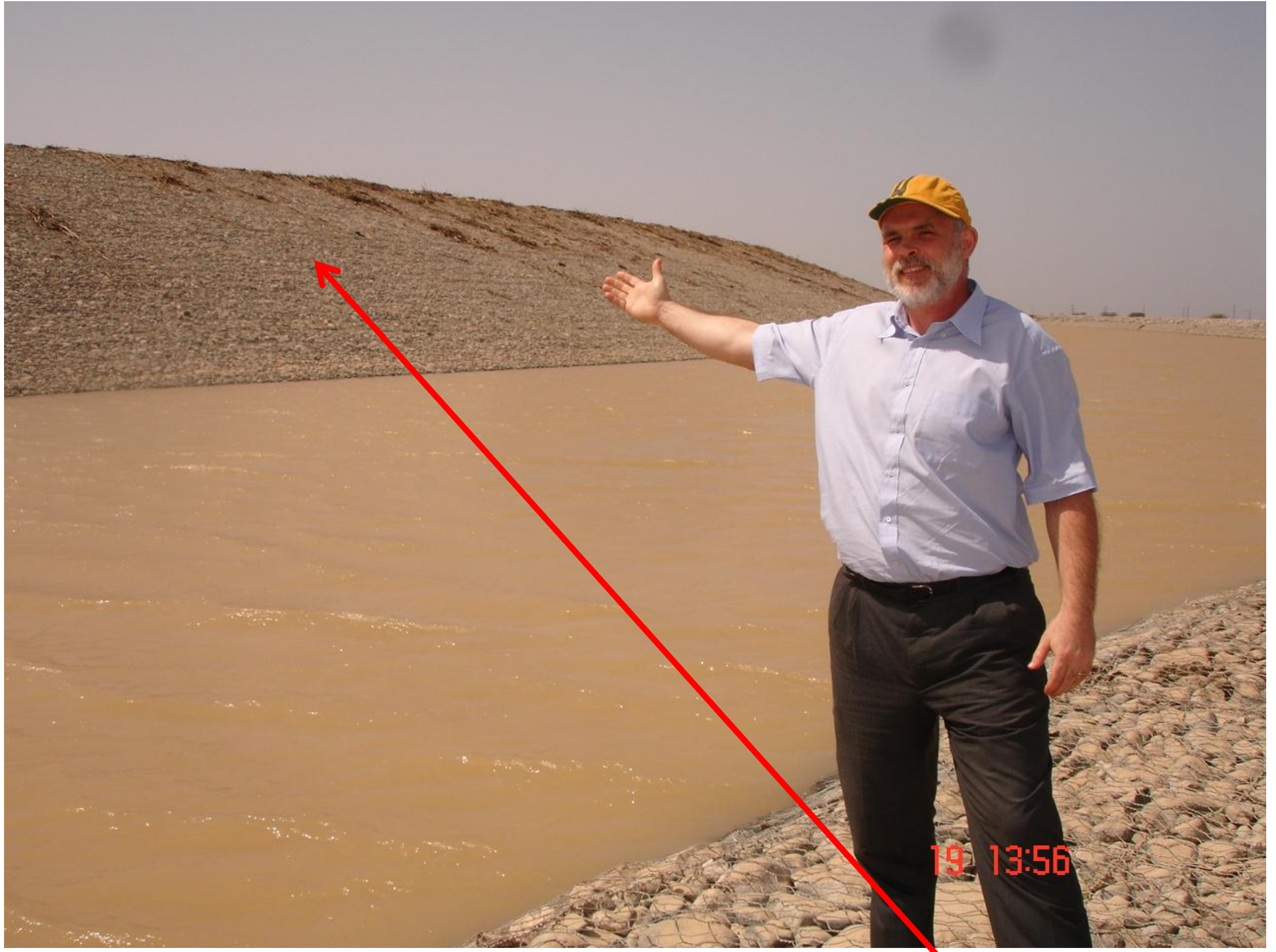

Stilling basin of the dam. Pre-Gonu flood of March 2007. The slope of the levee is sterile. Al-Khod dam. Area B. 


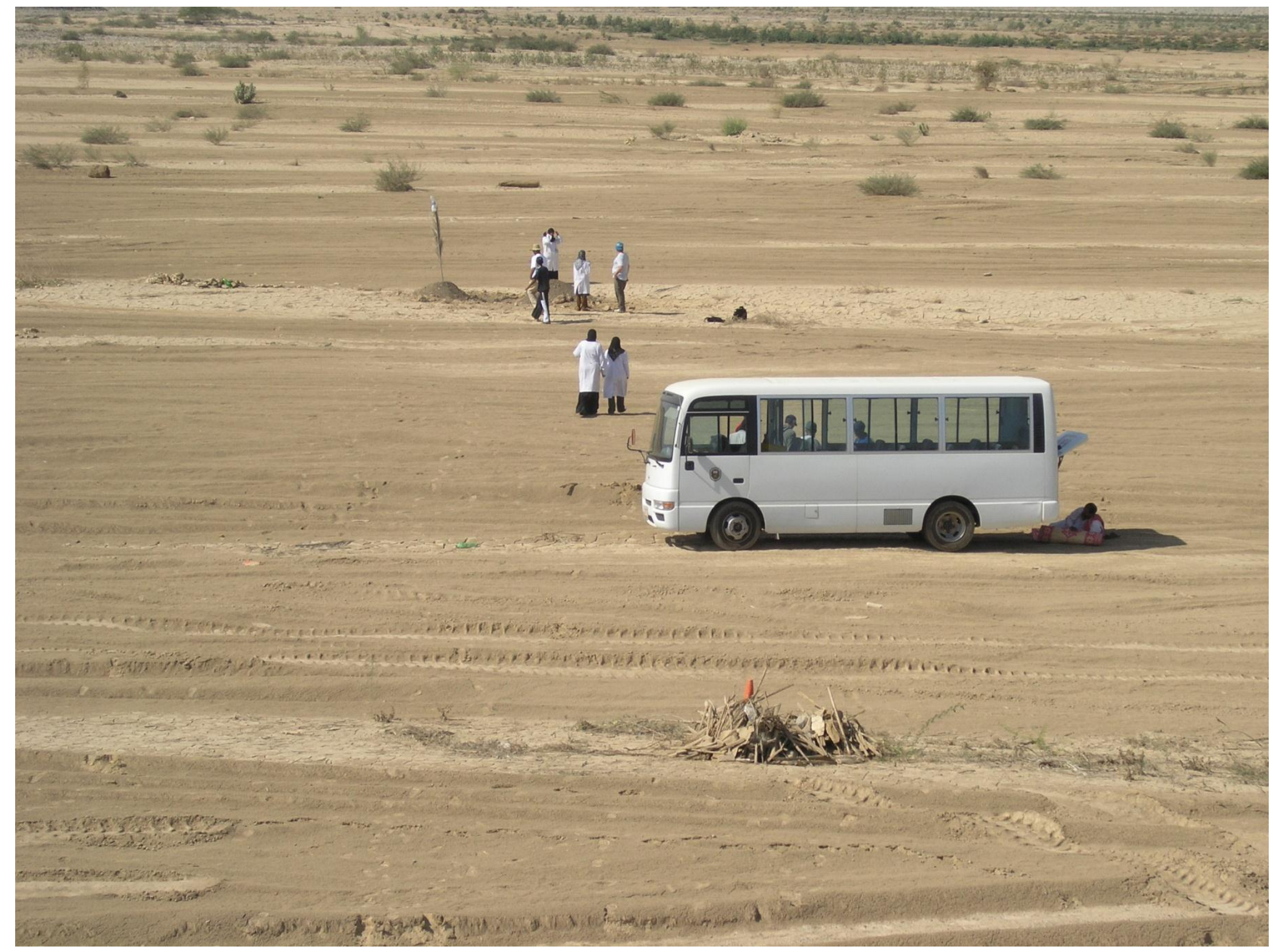

View of the reservoir area (Jan. 2009) from the crest of the embankment. Post-Gonu but pre-Phet vegetation is scattered. Al-Khod dam. Area A. 


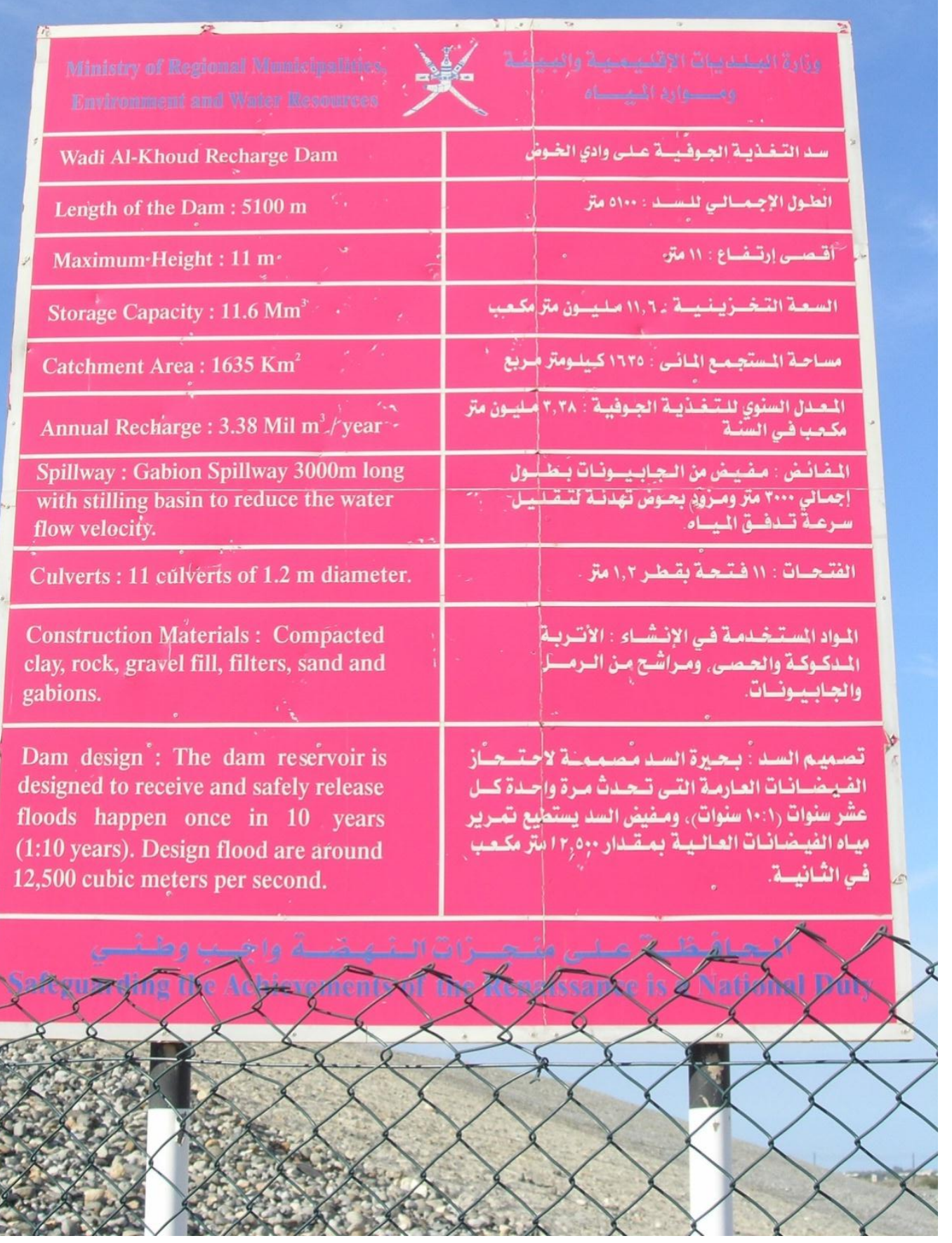

\section{Al-Khod dam data Area B.}




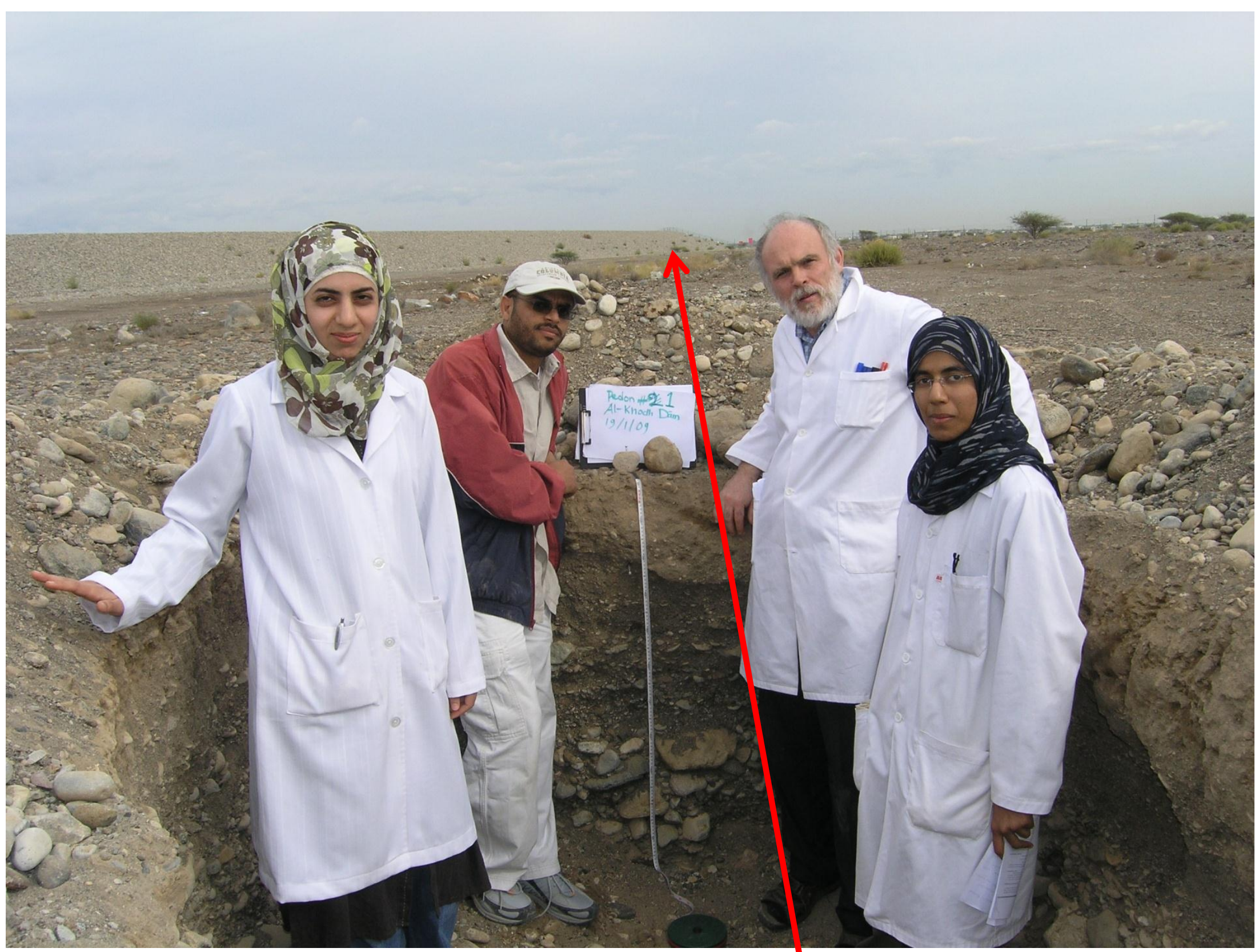

Pedon outside the dam area. Jan 2009. Incipient shrub community on the tailwater side. Al-Khod dam. Area A. 


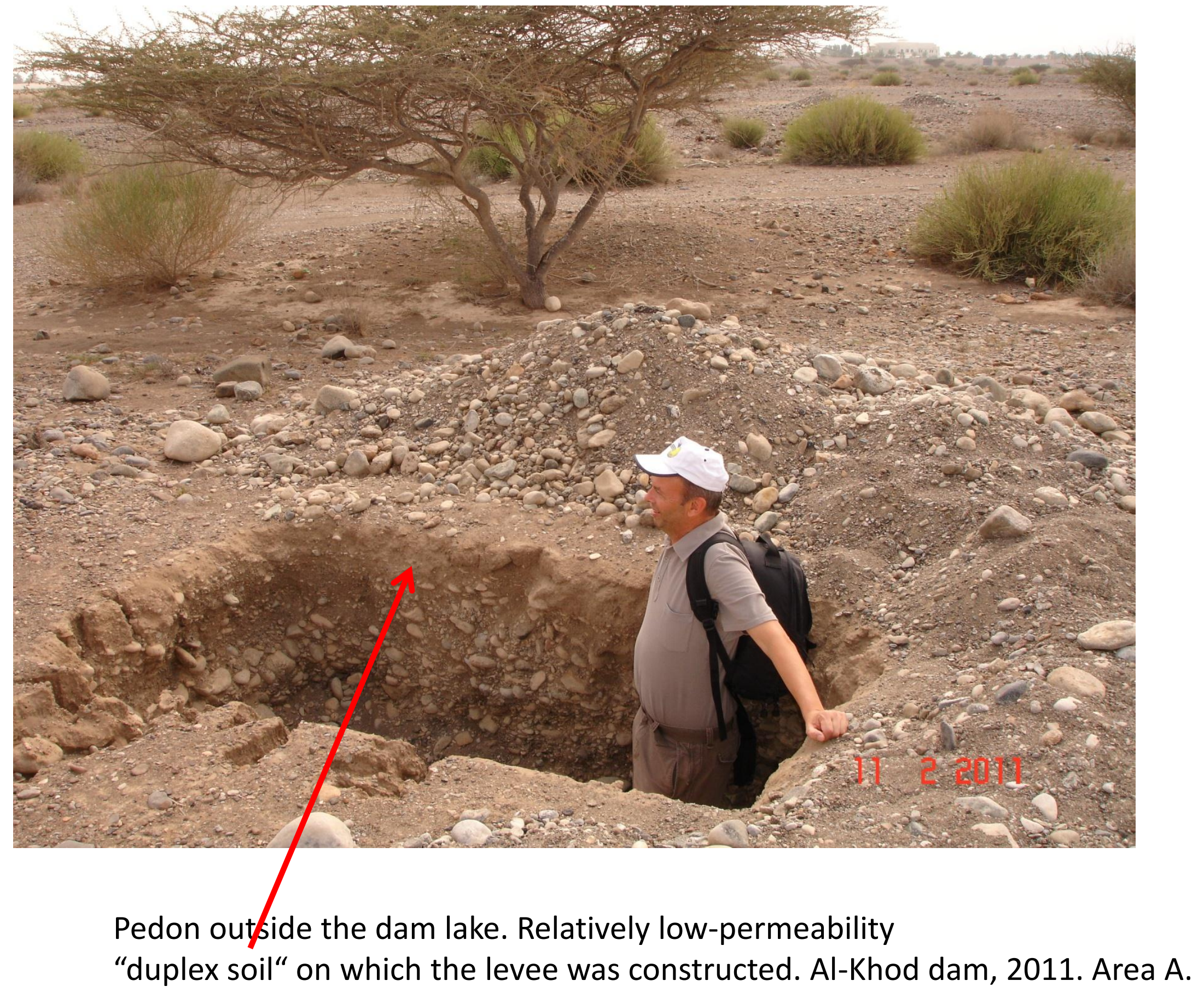




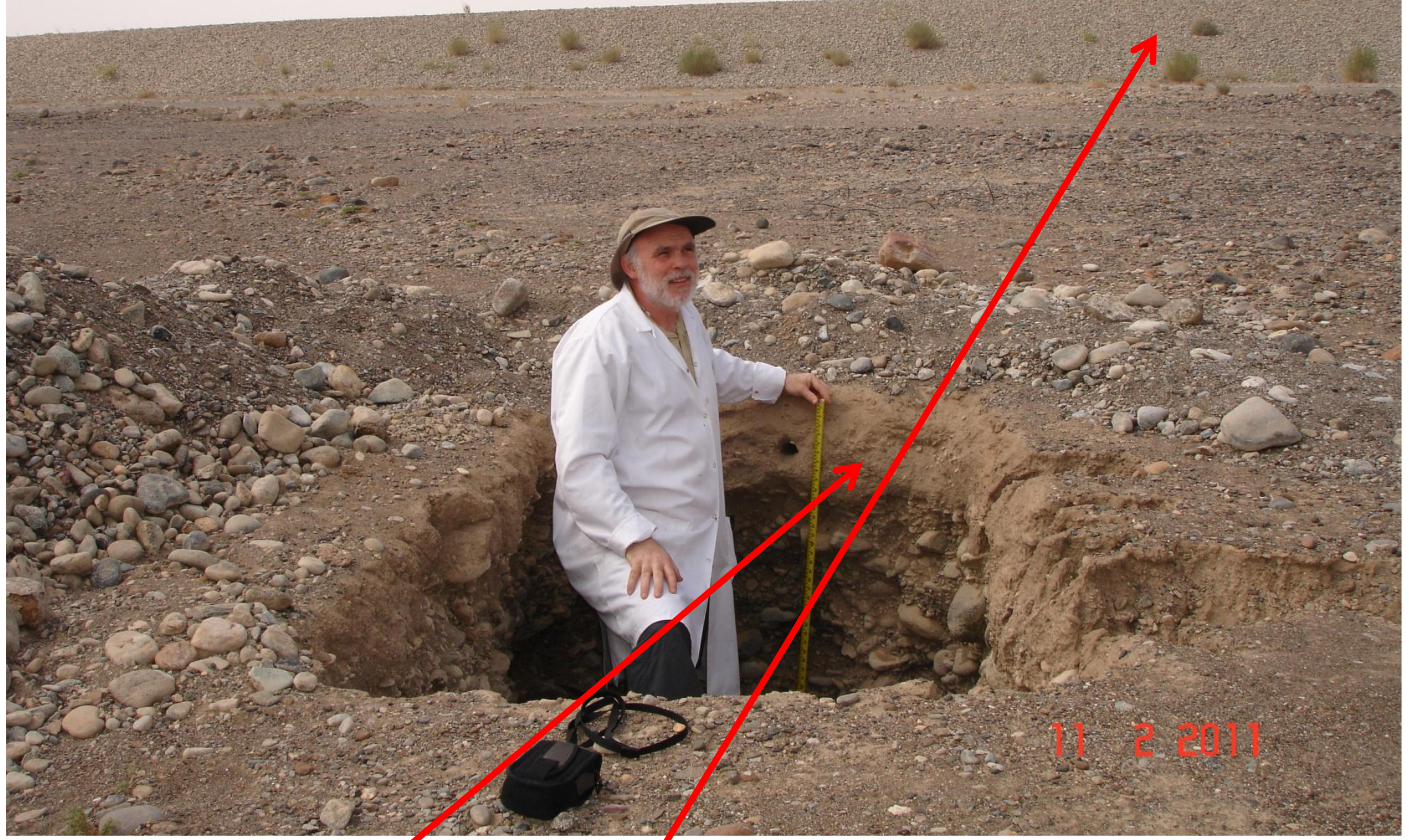

Pedon outside the dam lake. Relatively low-permeability "duplex soil" on which the levee was constructed. Al-Khod dam, 2011. Area A. 


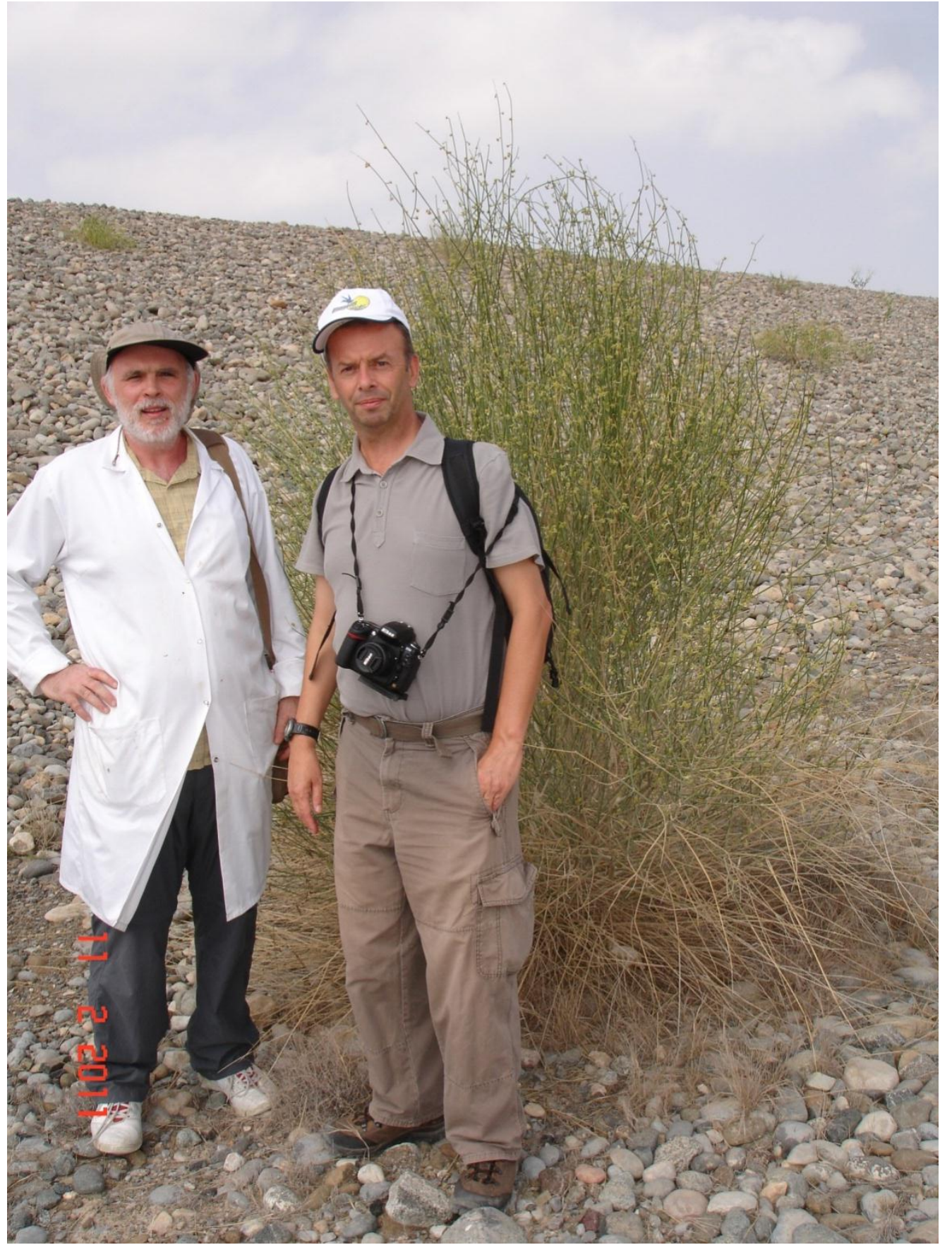

On the tailwater slope of the levee. Al-Khod dam, 2011. Area A. 


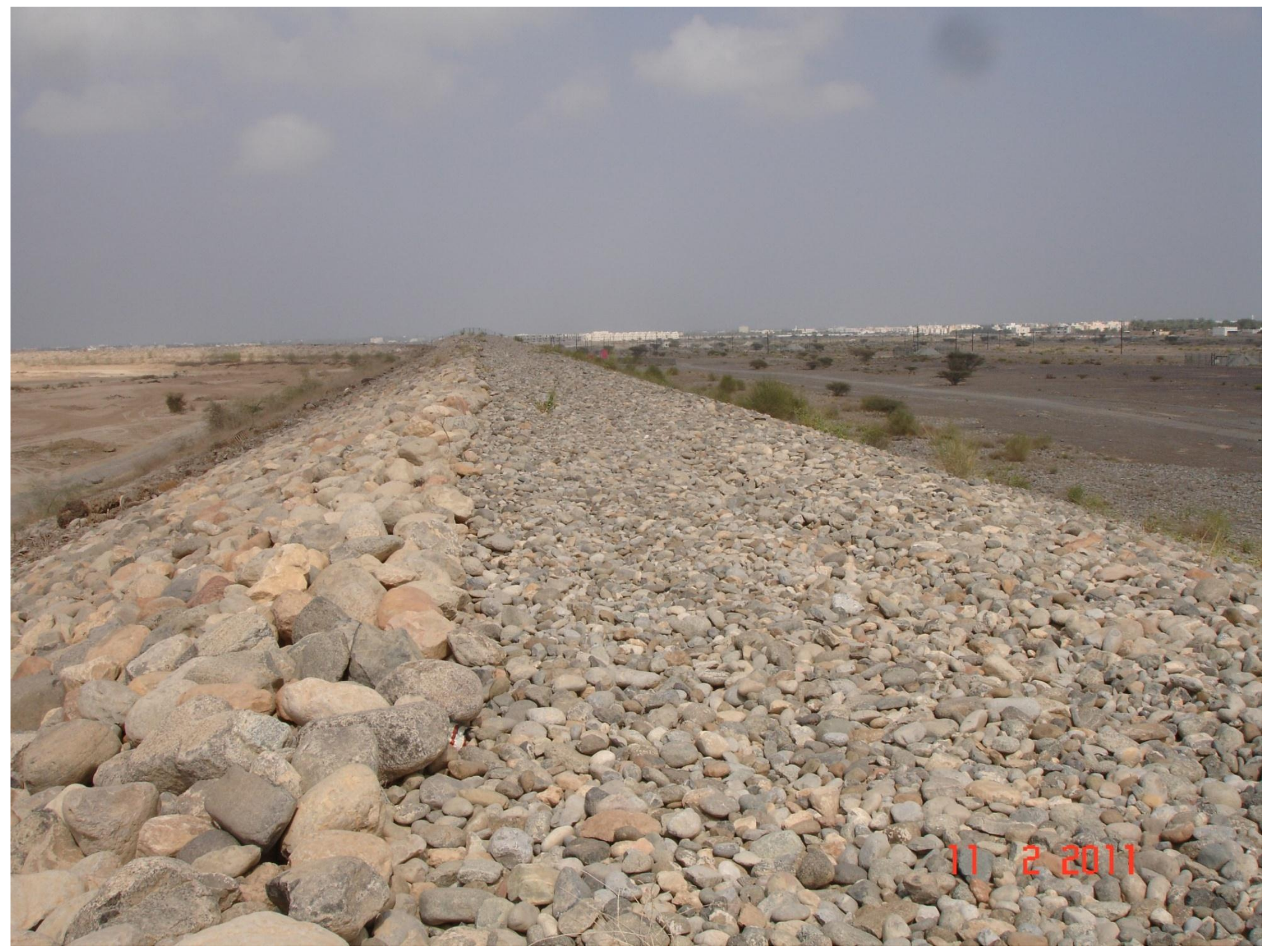

Embankment crest. Feb. 2011. Al-Khod dam. Area C. 


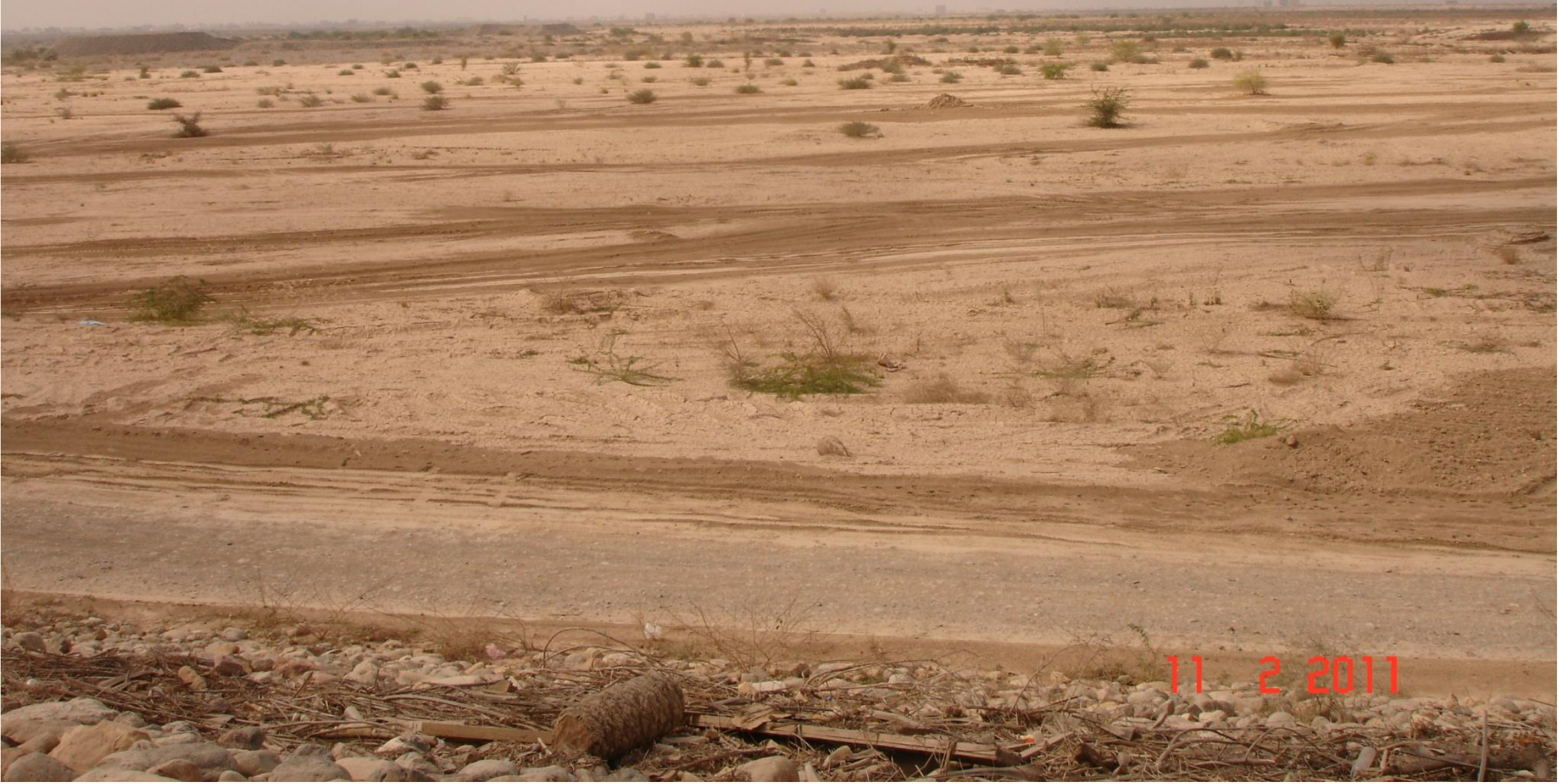

Reservoir area. View form the embankment crest. Al-Khod dam 2011. Area A. 


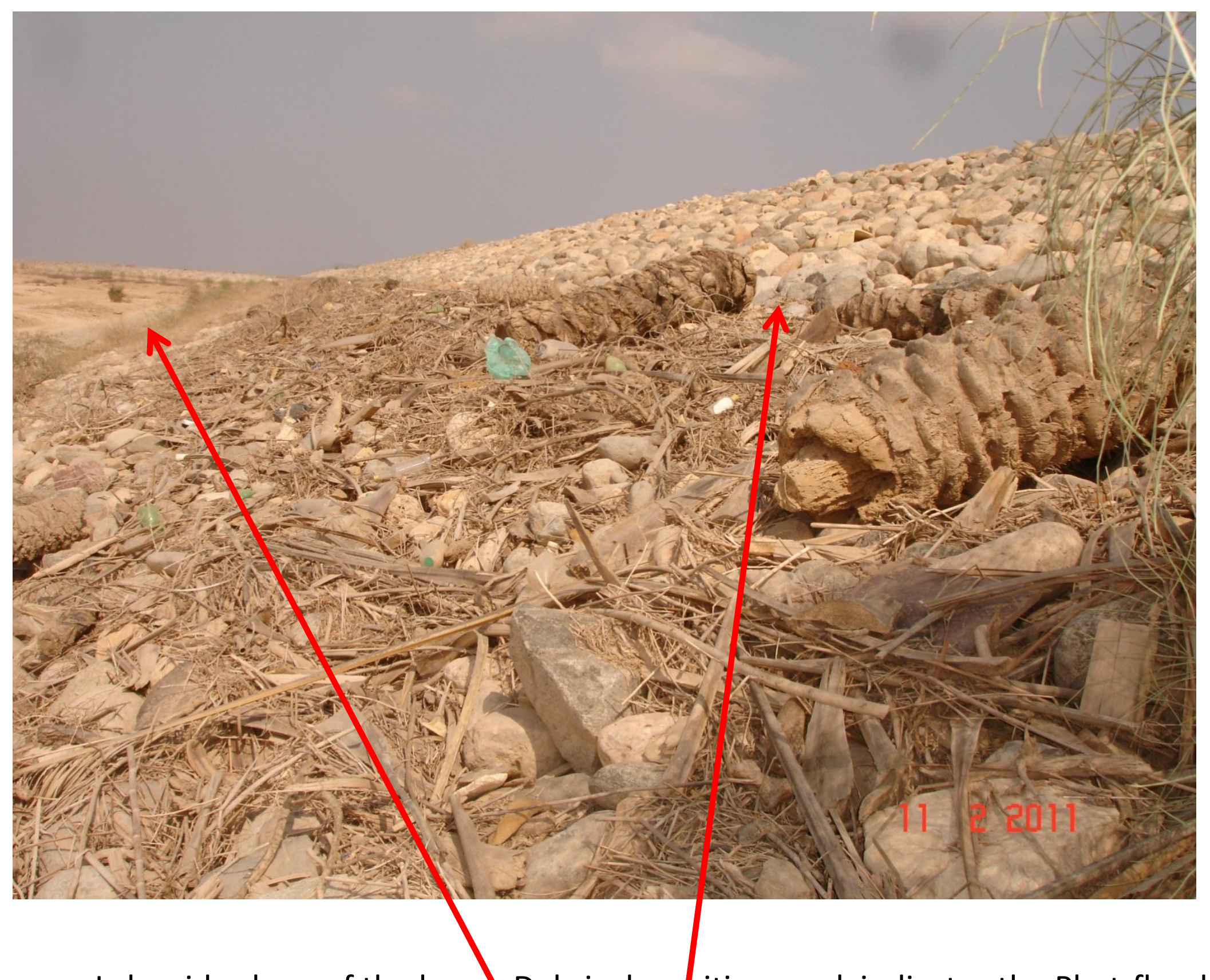

Lake-side slope of the levee Debris deposition mark indicates the Phet-flood (2010) highest water level. The band of scrub is close to the toe. Al-Khod dam. Area A. 


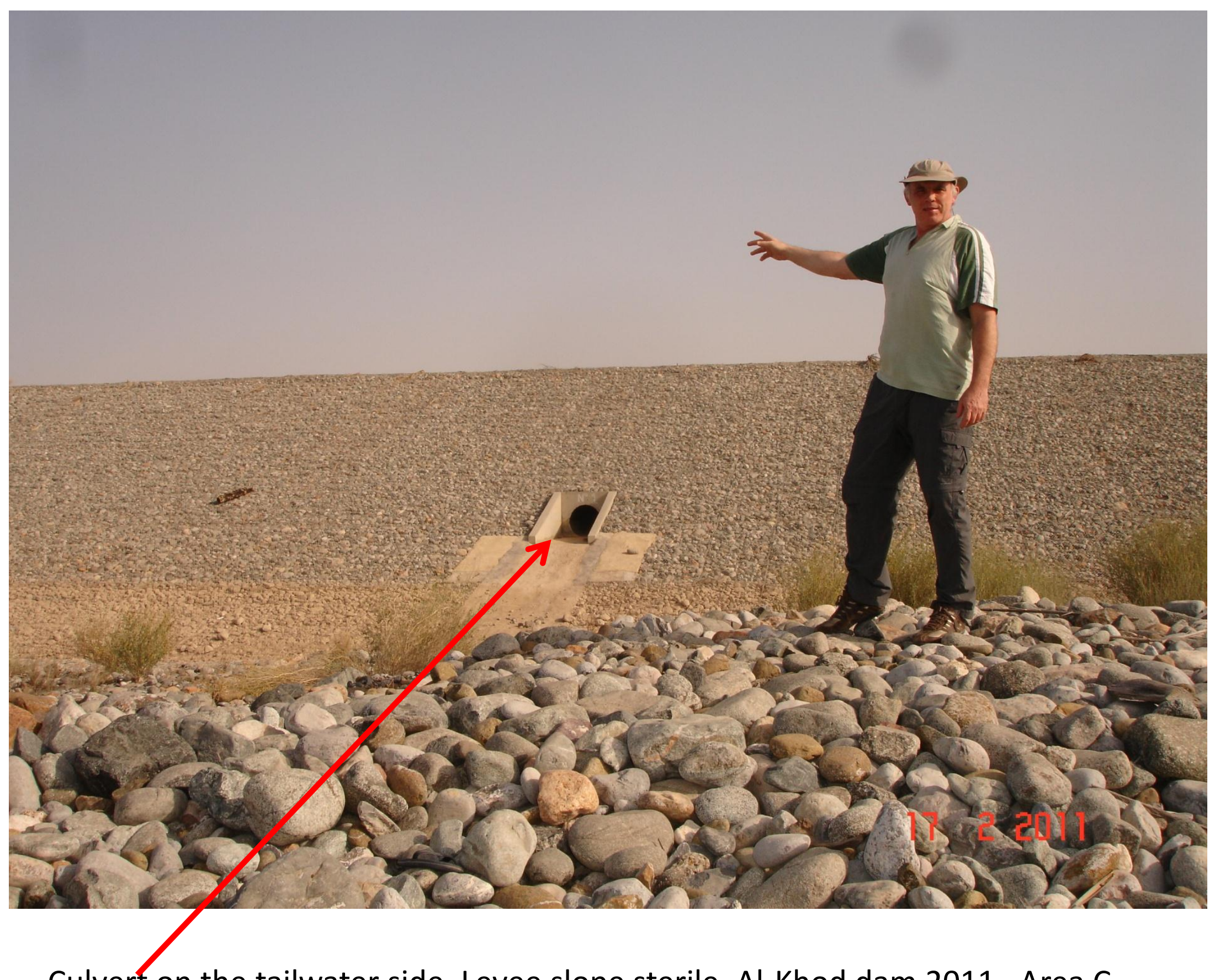

Culvert on the tailwater side. Levee slope sterile. Al-Khod dam 2011. Area C 


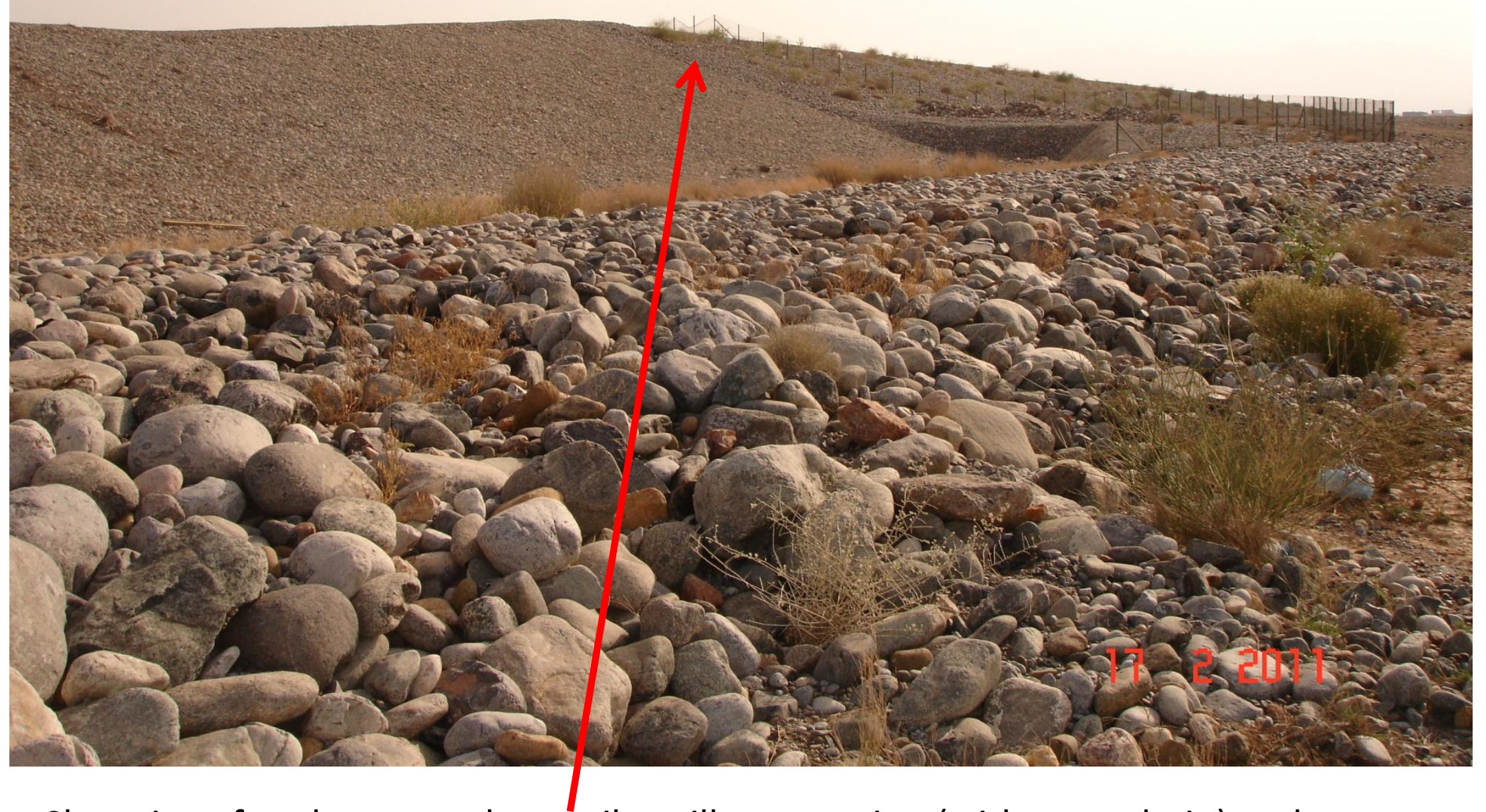

Sharp interface between the sterile spillover section (with a toe drain) and green undrained levee section. Al-Khod dam, Feb.2011. Area C. 


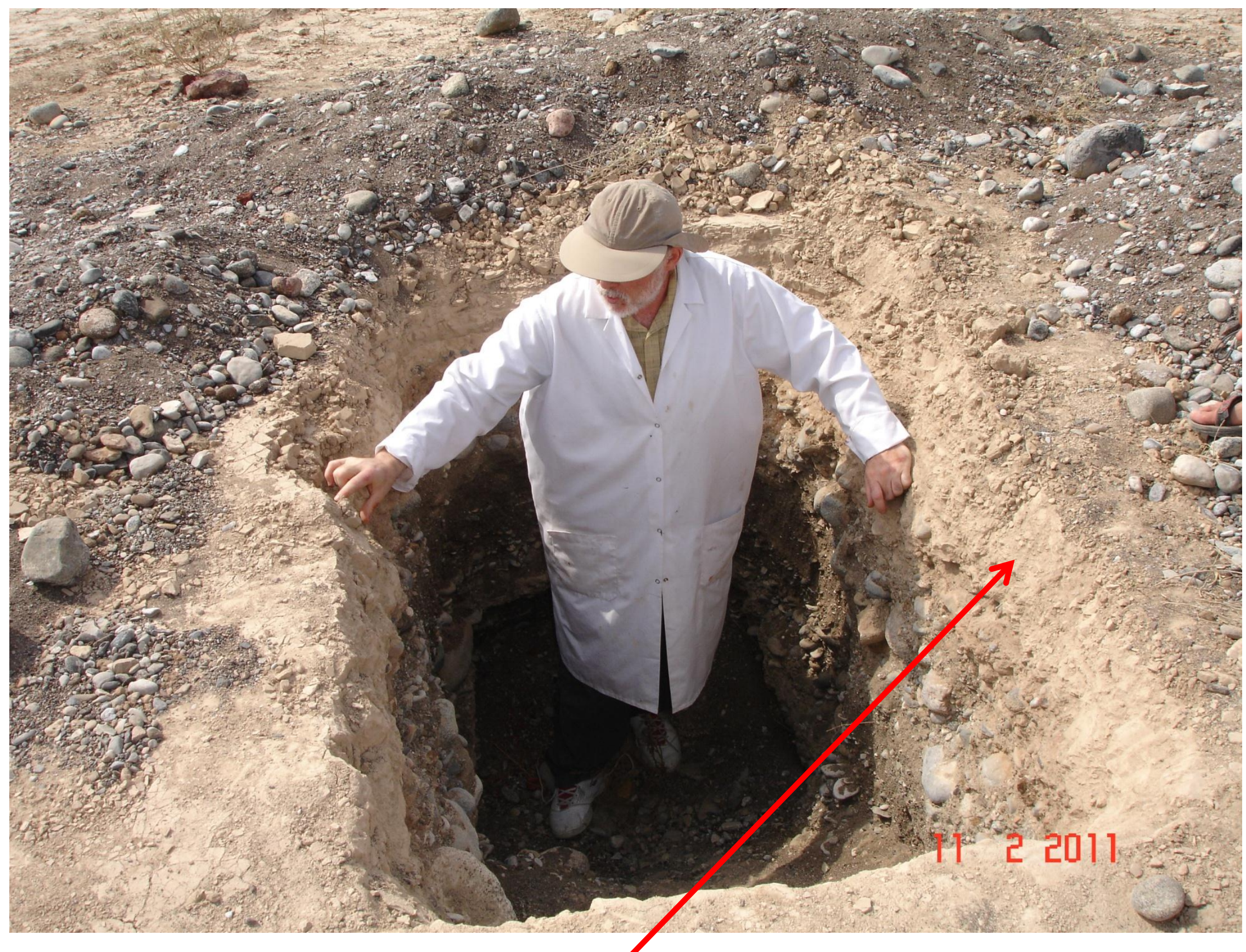

Pedon inside the dam lake. Silt cake. Al-Khod dam, 2011. Area B. 


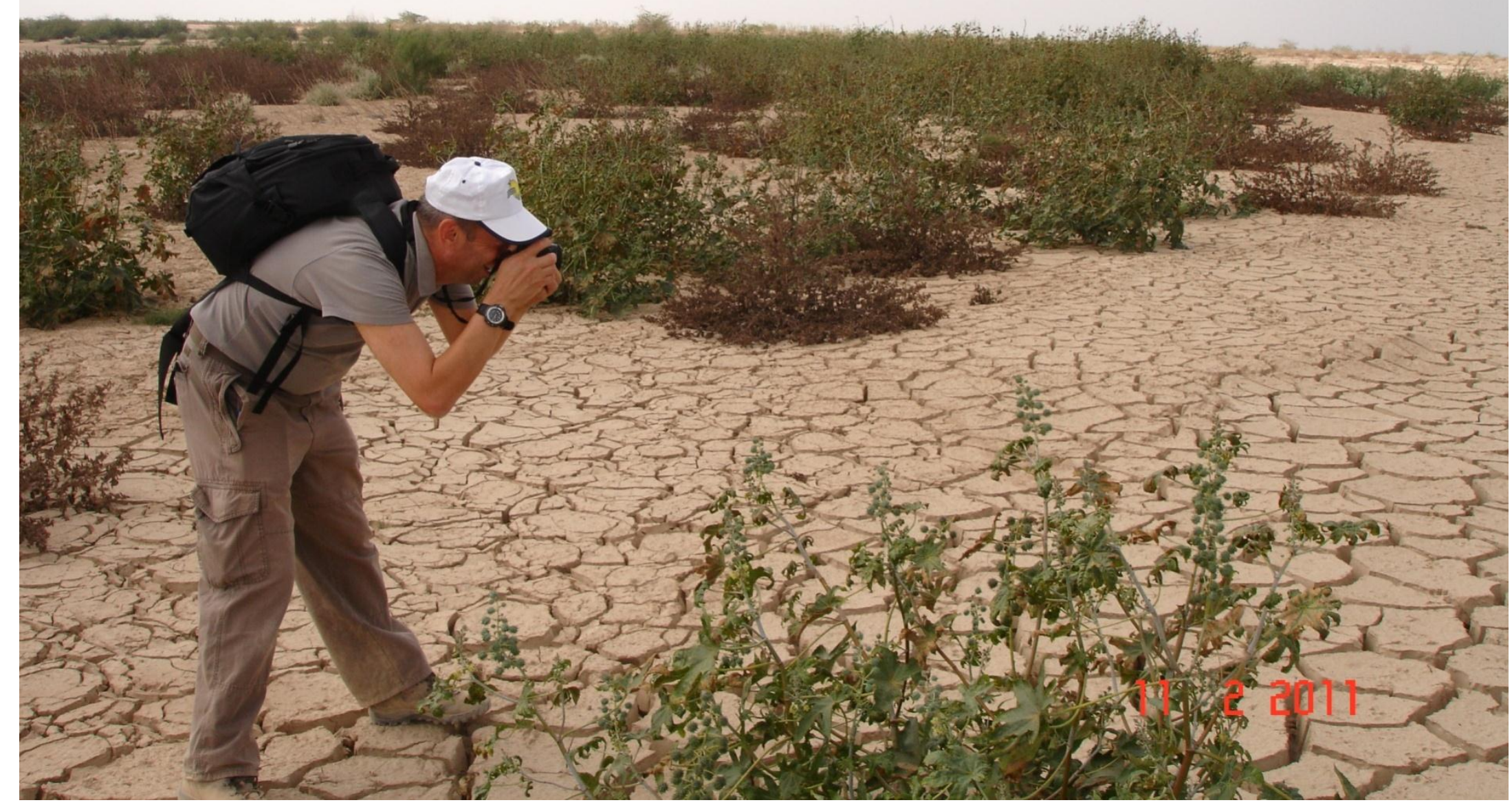

Vegetation on the lake bottom. Al-Khod dam 2011. Area B. 


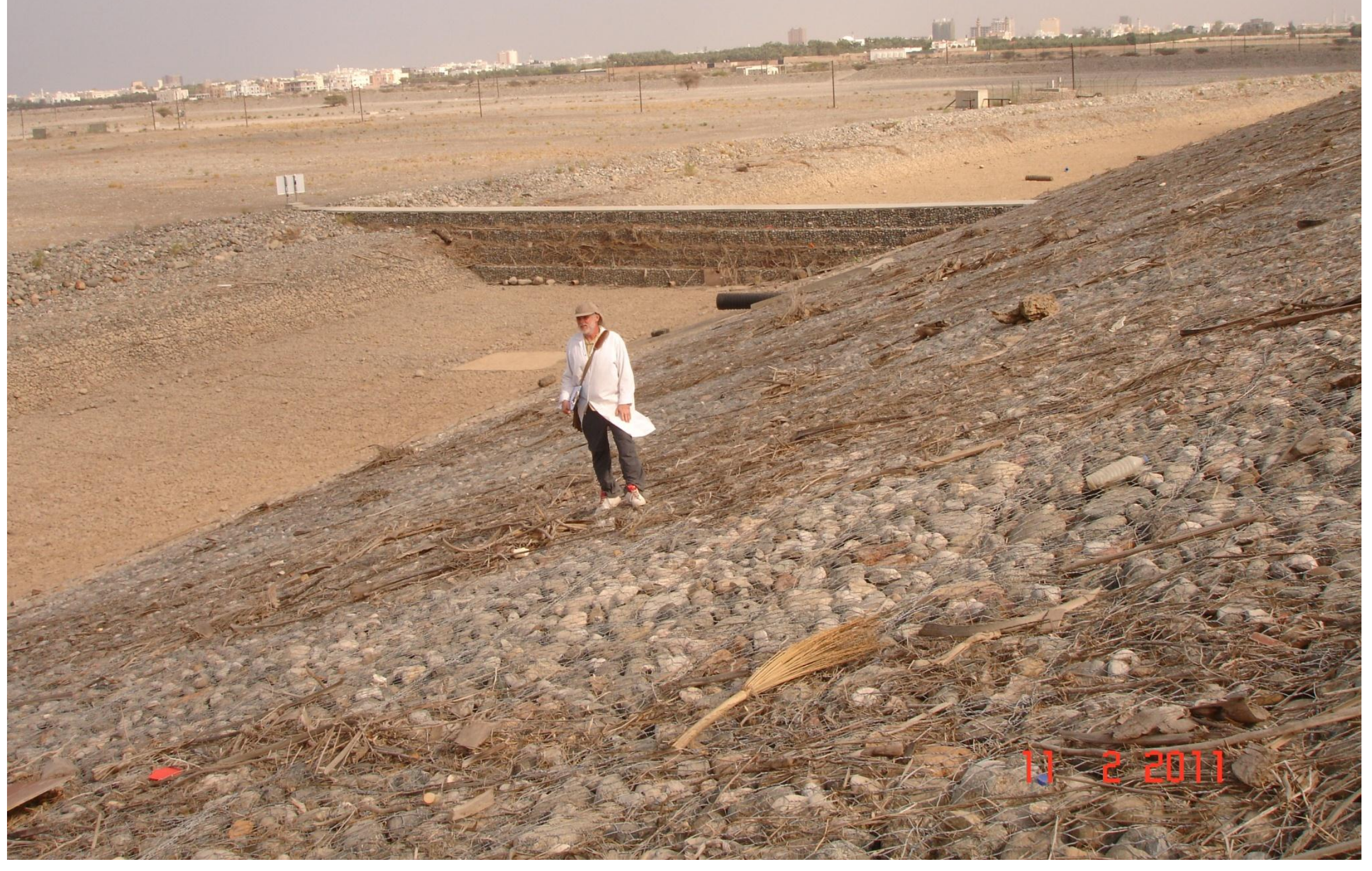

External slope (stilling basin side) of the levee. Sterile. Al-Khod dam 2011. Area B. 


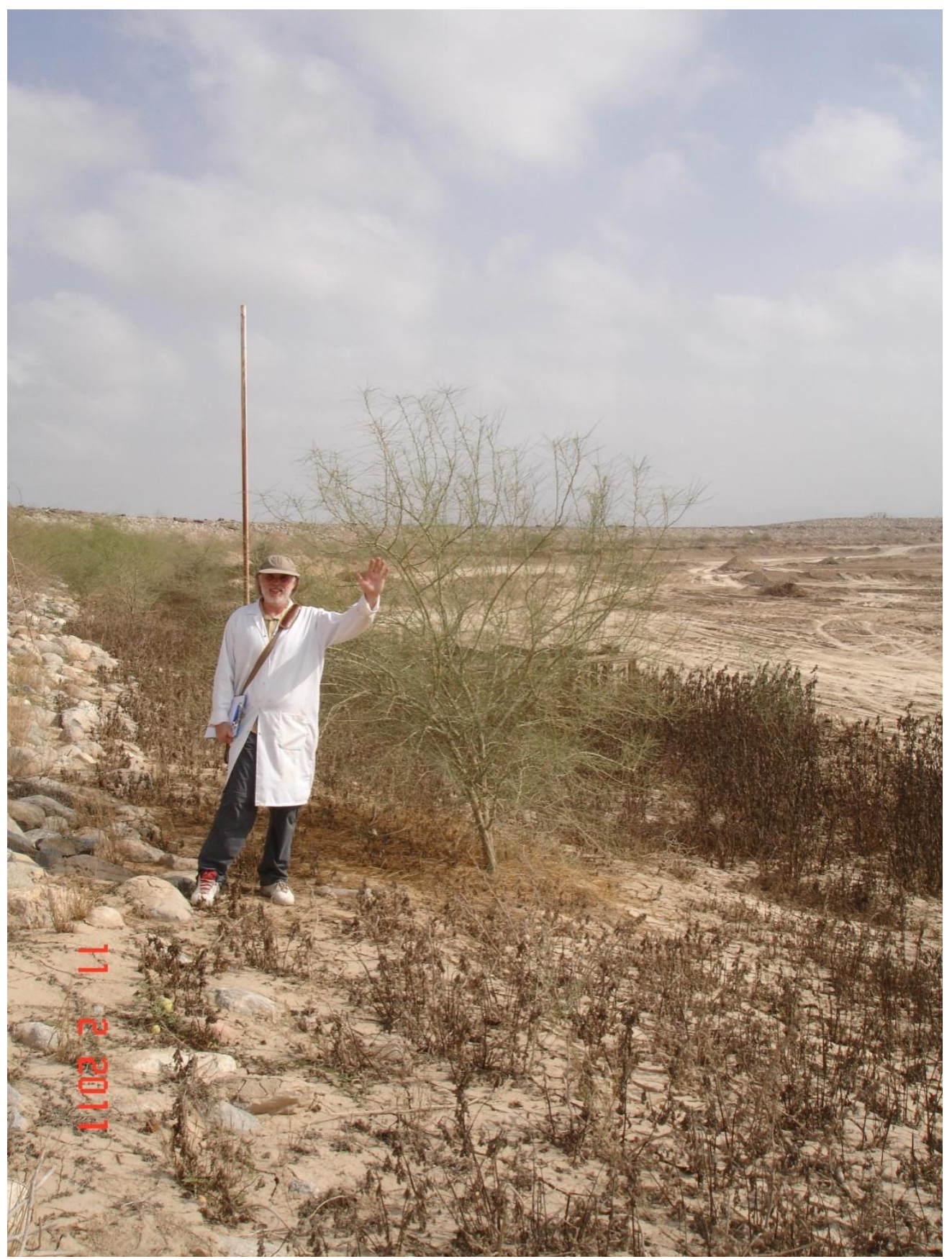

Band of scrub on the lake-side slope of the levee. Al-Khod dam, 2011. Area B 


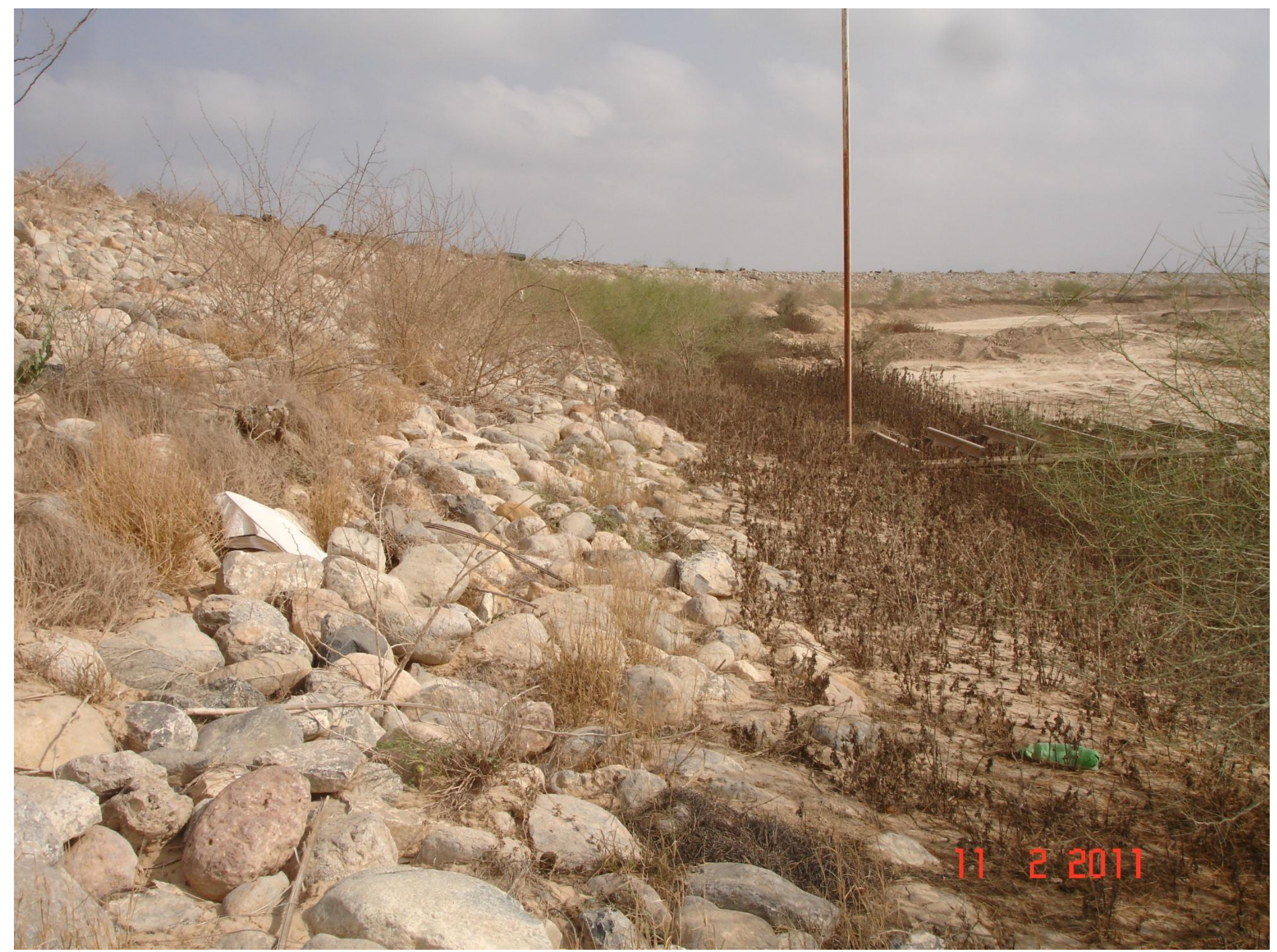

Band of scrub on the lake-side slope of the levee near the sluice gate. Al-Khod dam, 2011. Area B. 


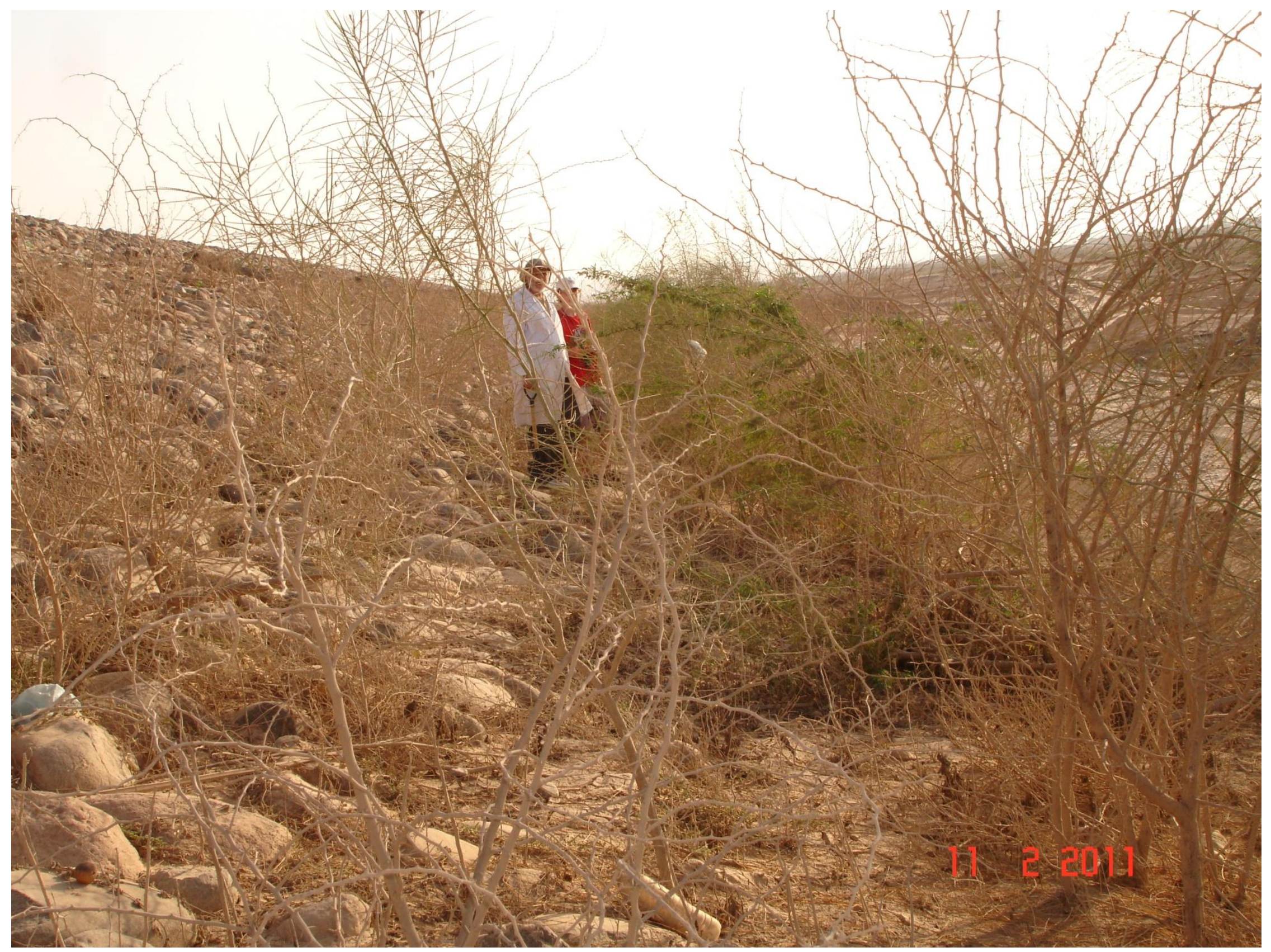

Band of scrub on he lake-side slope of the levee. Picture from inside the band. Al-Khod dam, 2011. Area A. 


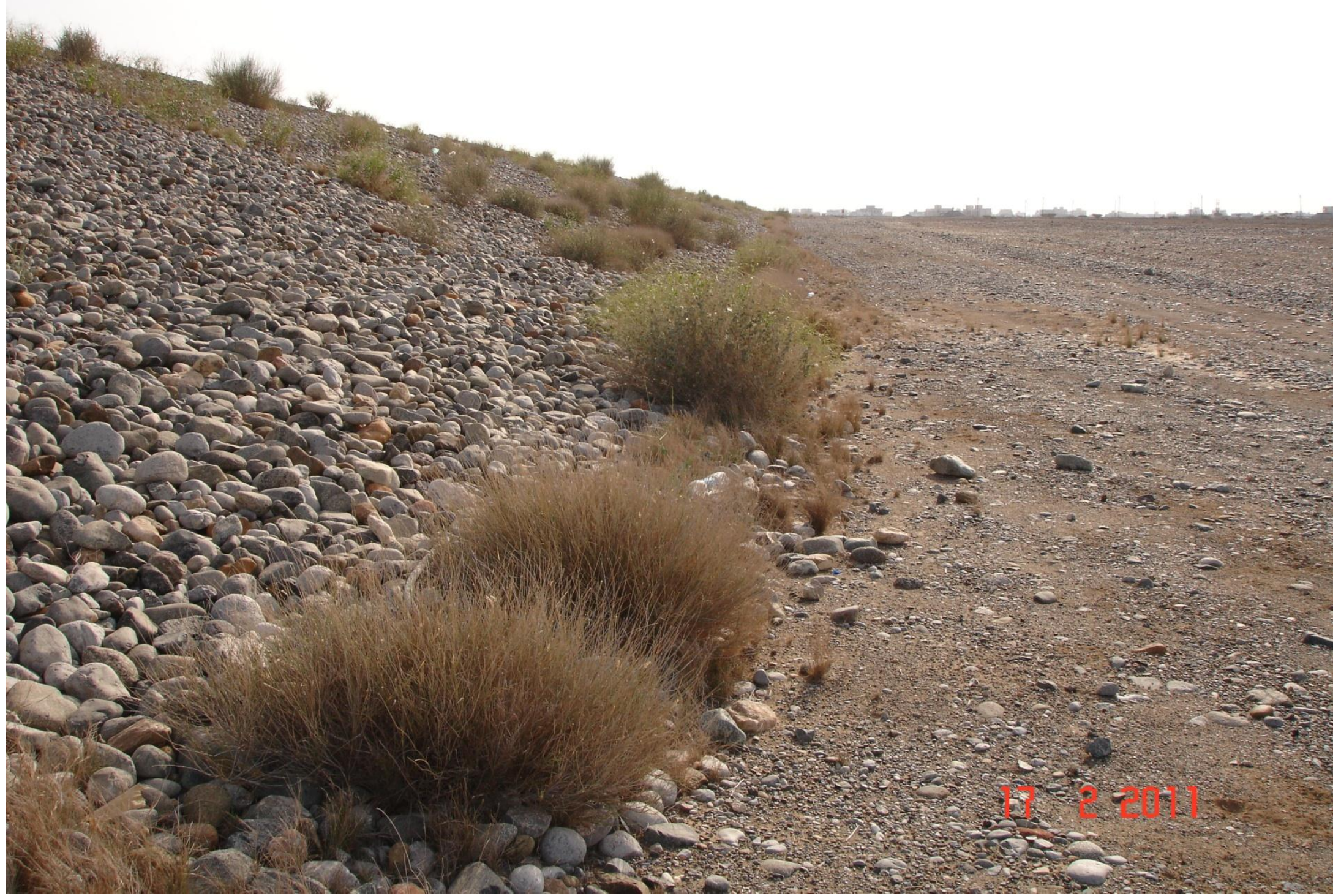

Band of vegetation. Feb 2011. Al-Khod dam. Tailwater slope. Area C. 


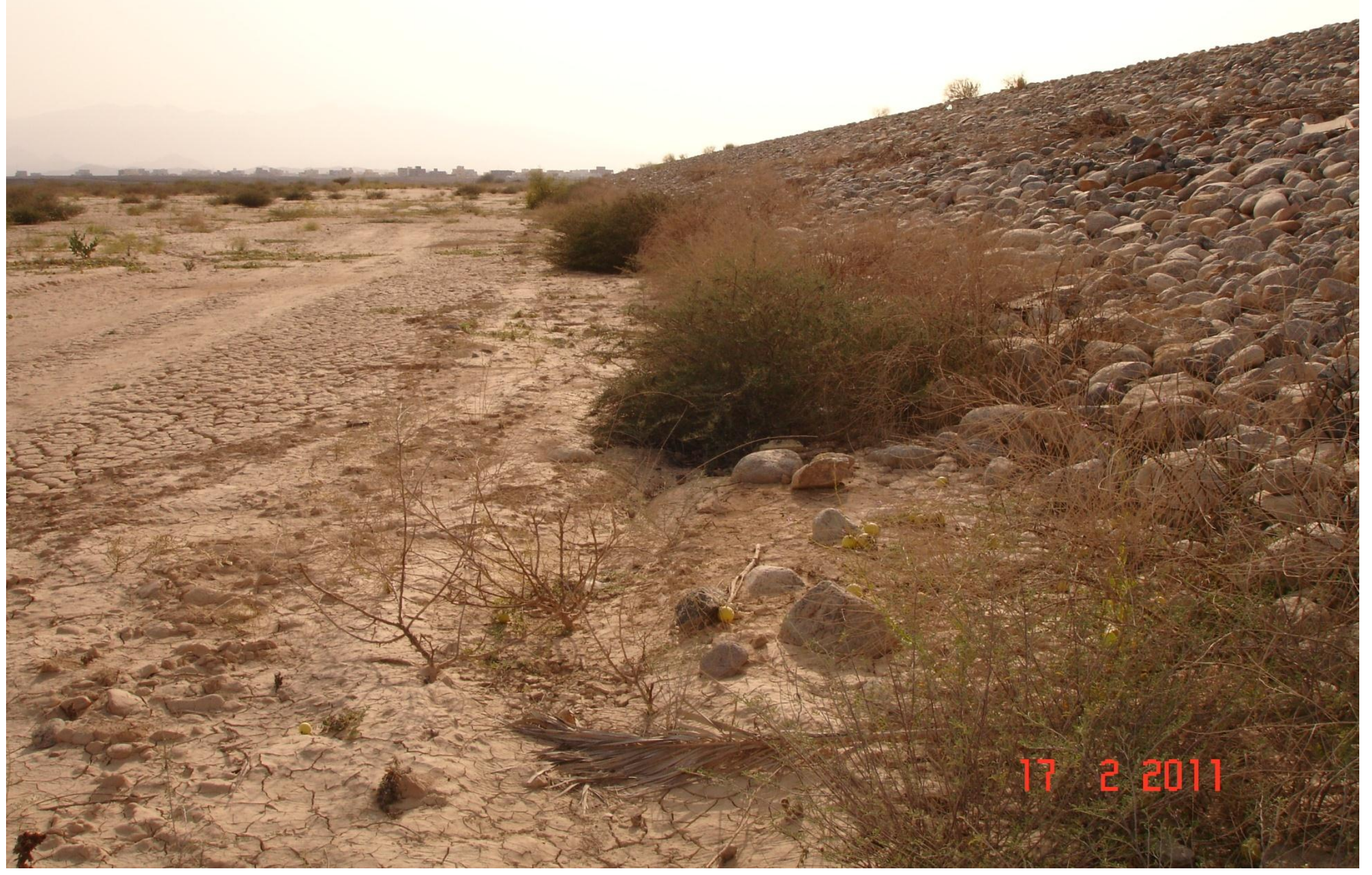

Band of vegetation. Feb 2011. Al-Khod dam. Like-side slope. Area C. 


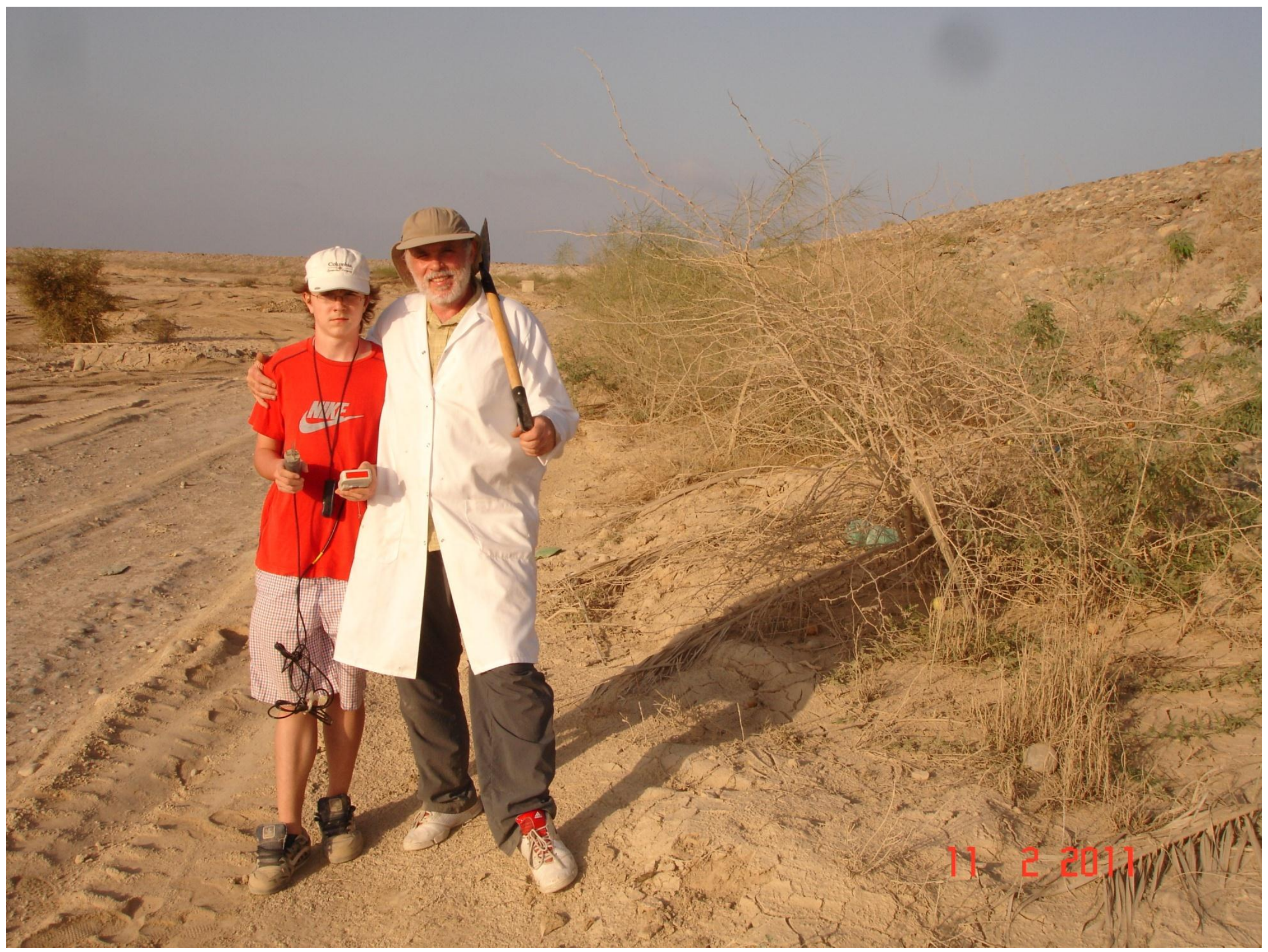

Band of scrub on he lake-side slope of the levee. Moisture content measurements Al-Khod dam, 2011. Area A. 


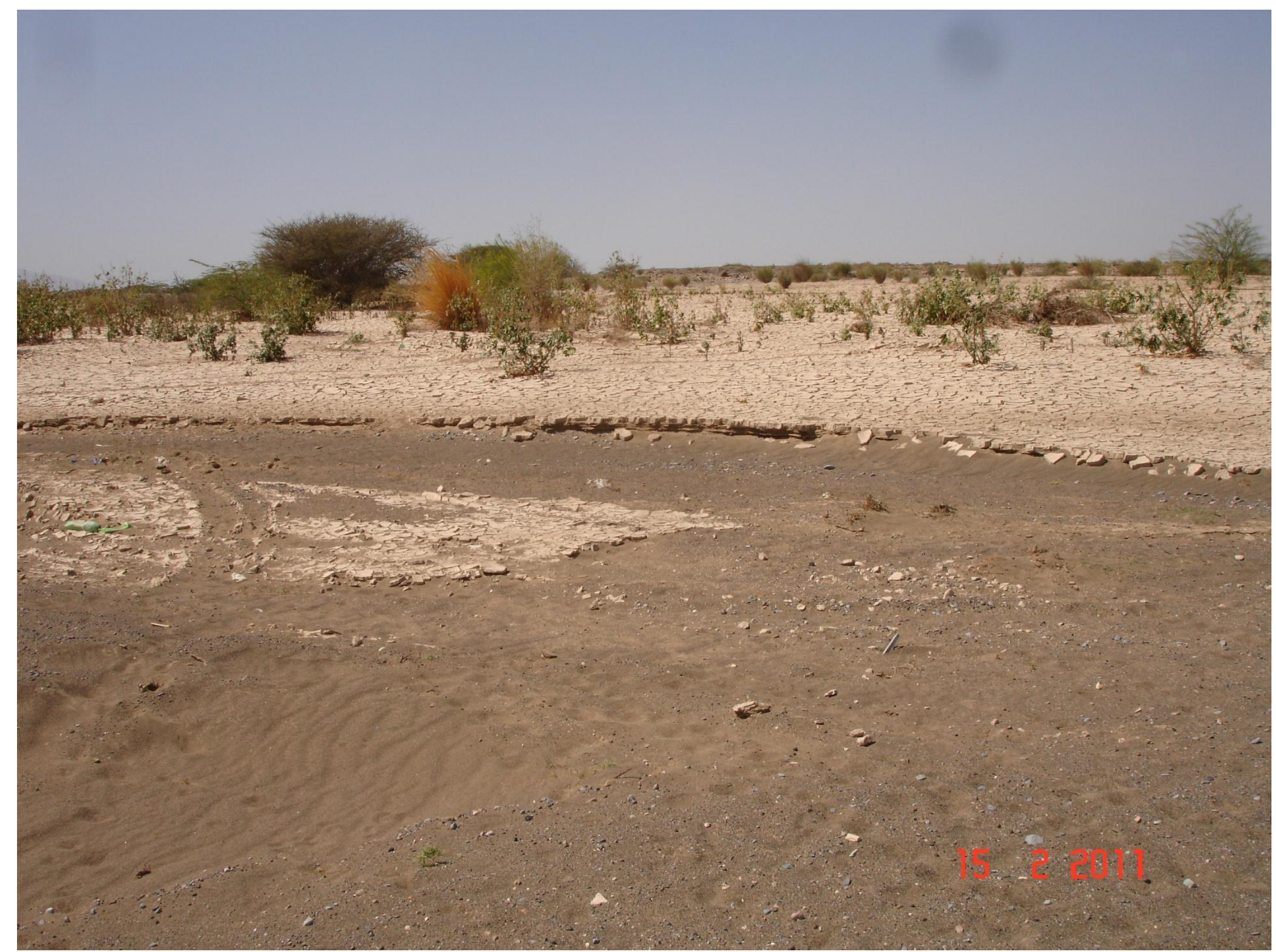

Main wadi course. Al-Khod dam, February 2011. Area C. 


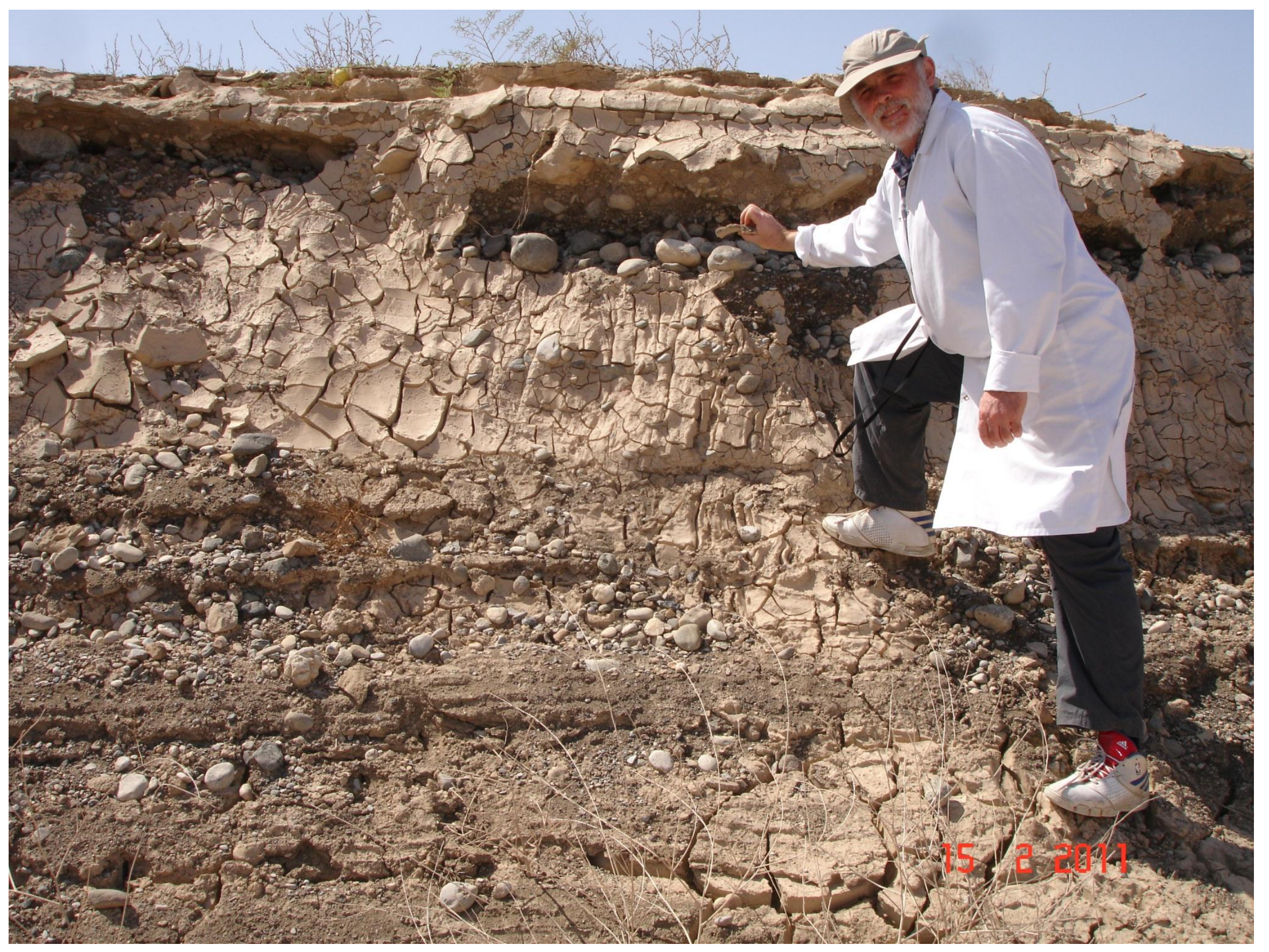

Slope of an artificial excavation in the lake area. Al-Khod dam, February 2011. Area A. 


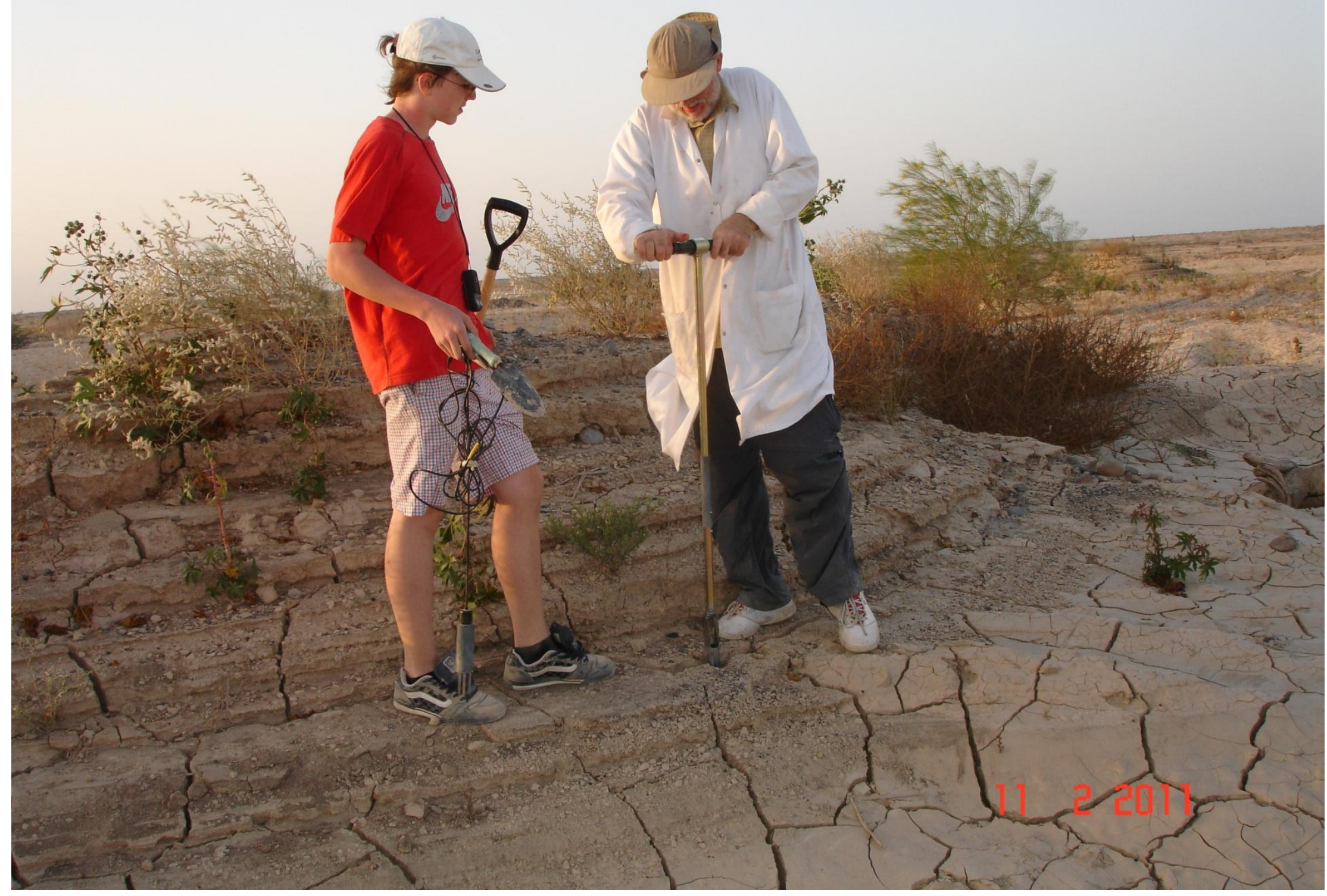

Soil sampling. Al-Khod dam 2011. Area A. 


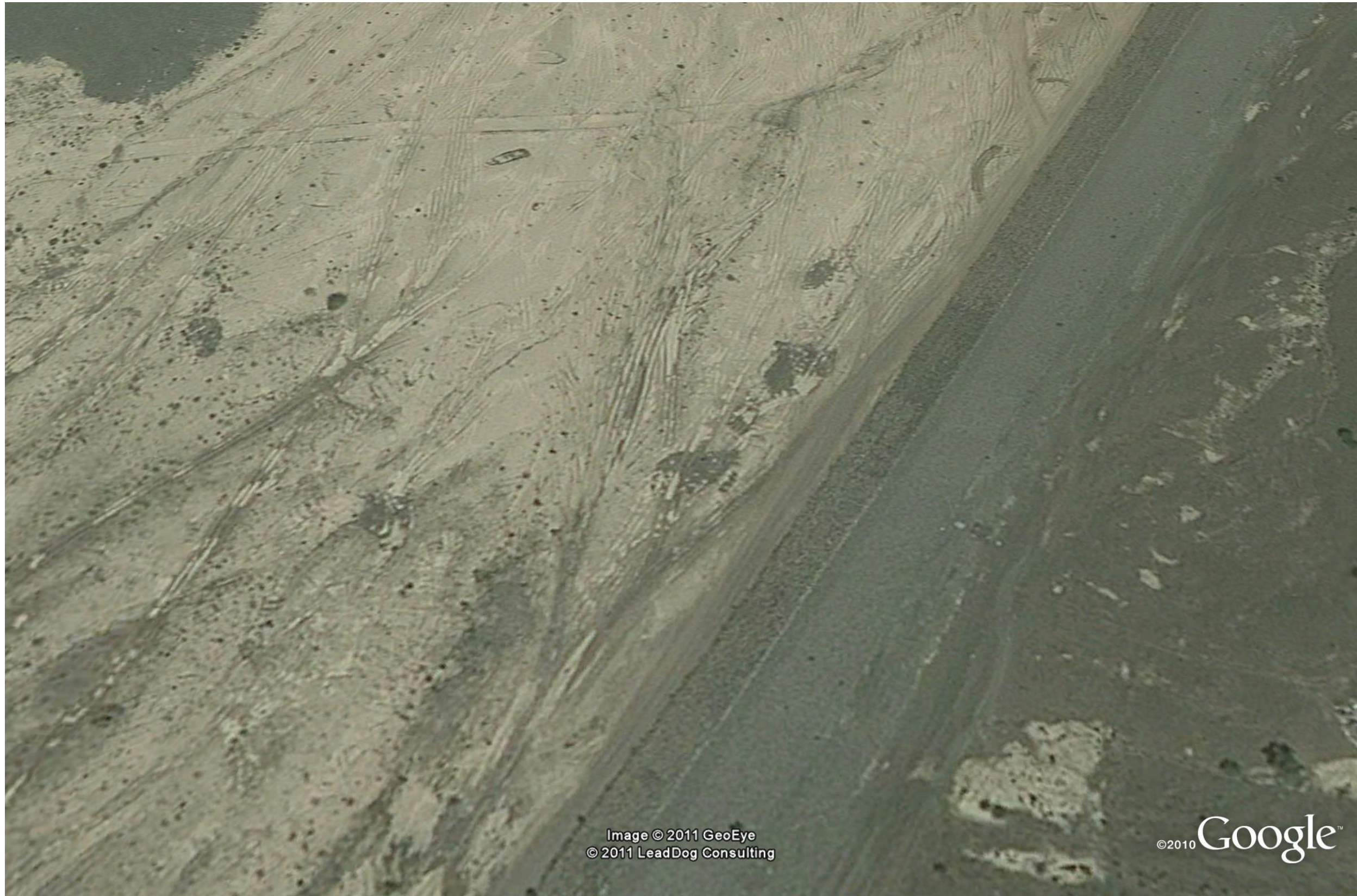

Al-Khod dam, Area A. February 2010. 


\section{LAKE ECOSYSTEM}

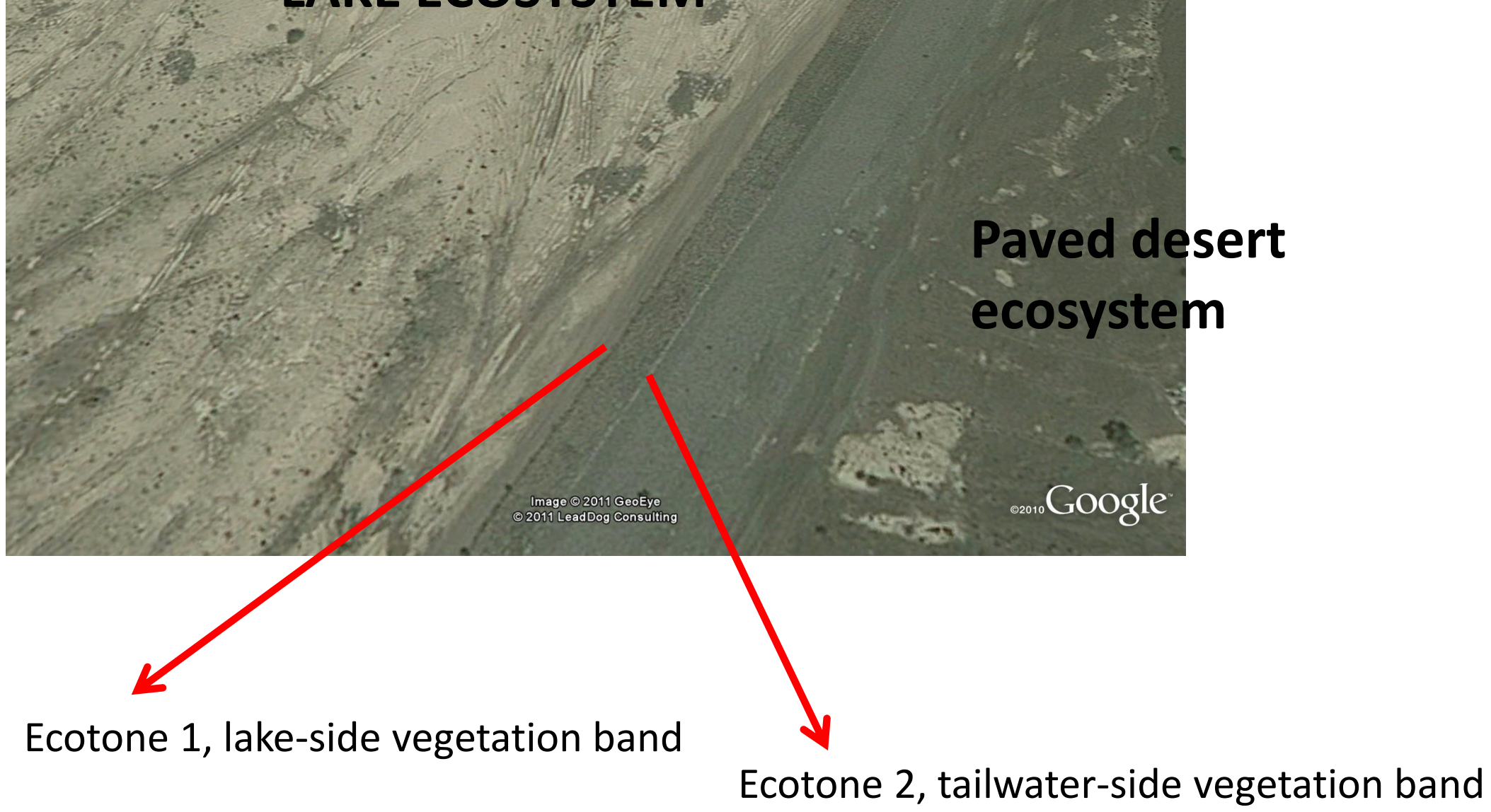




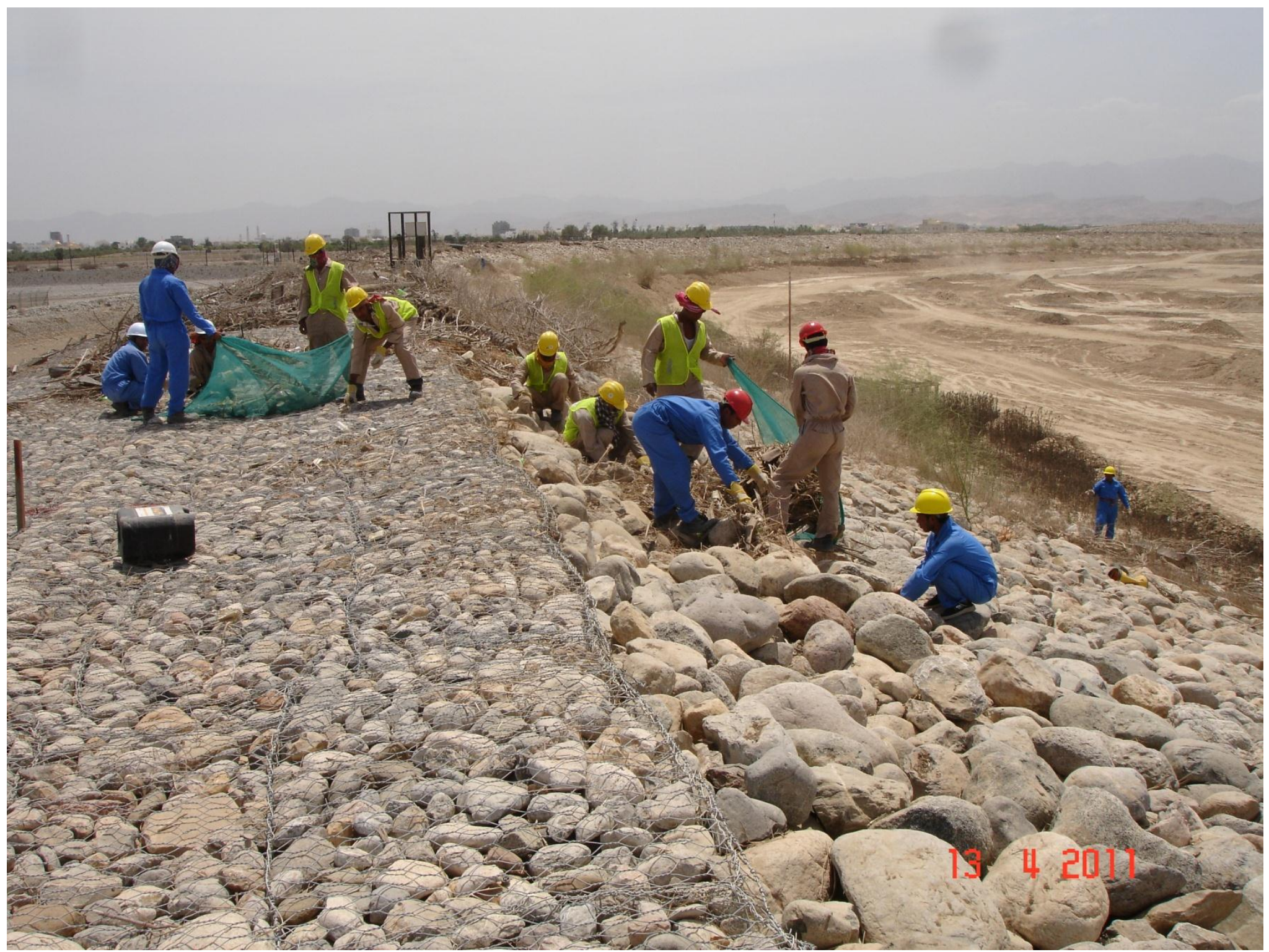

April-May 2011: Extermination of vegetation (engineering intervention into an pre-engineered "homeostasis") 
November 2011: Post-extermination re-emergence of the vegetation strip

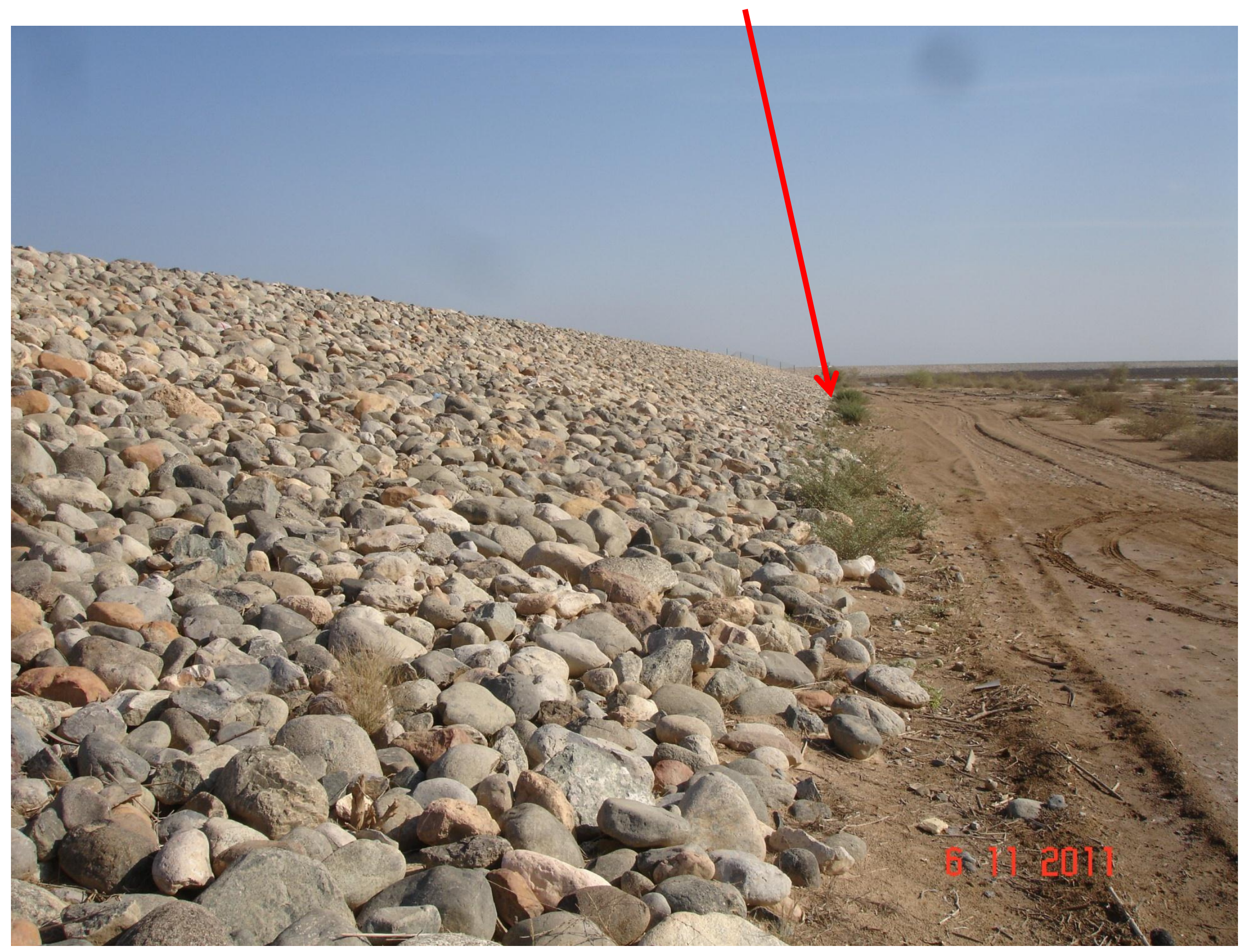




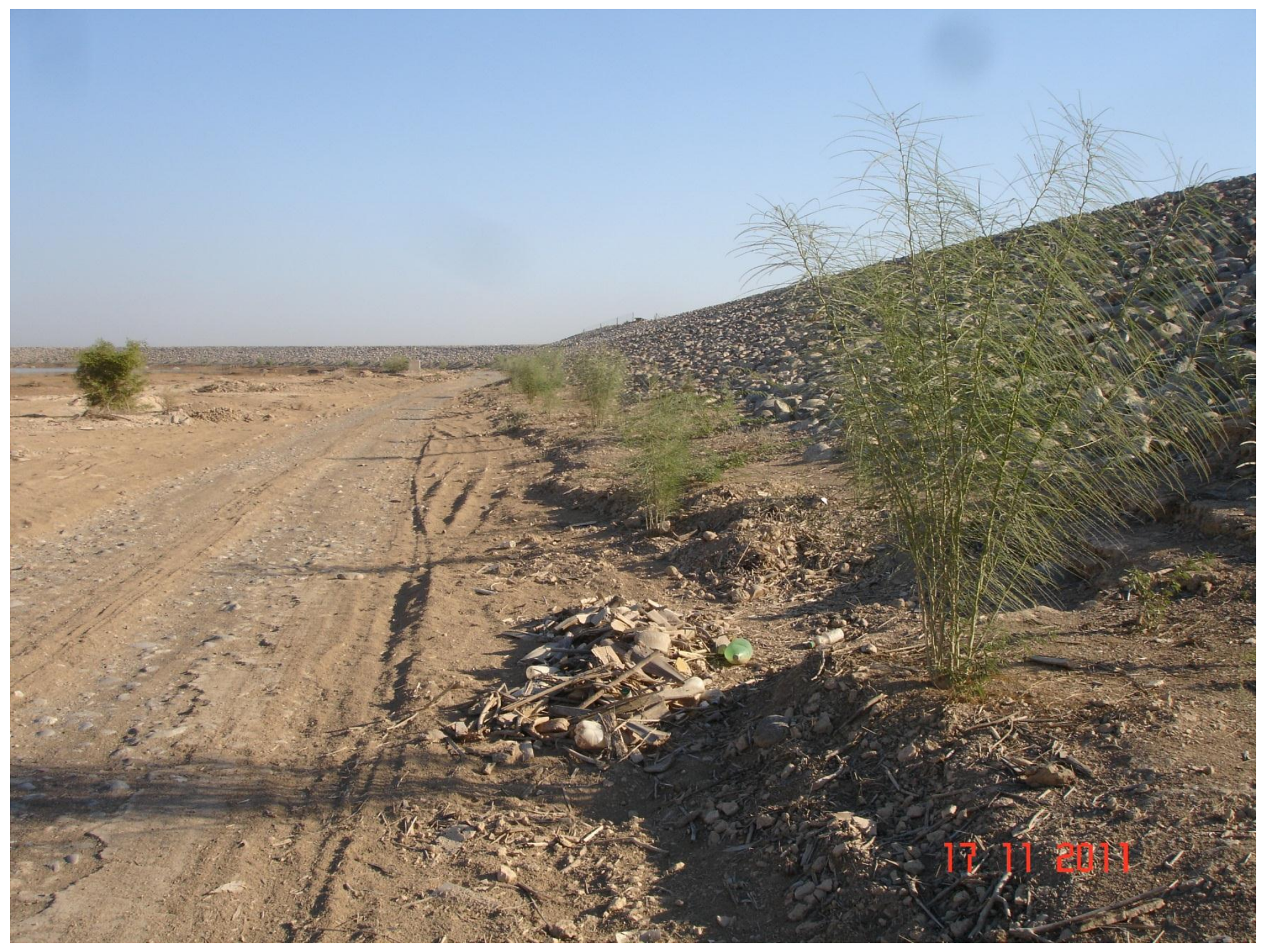




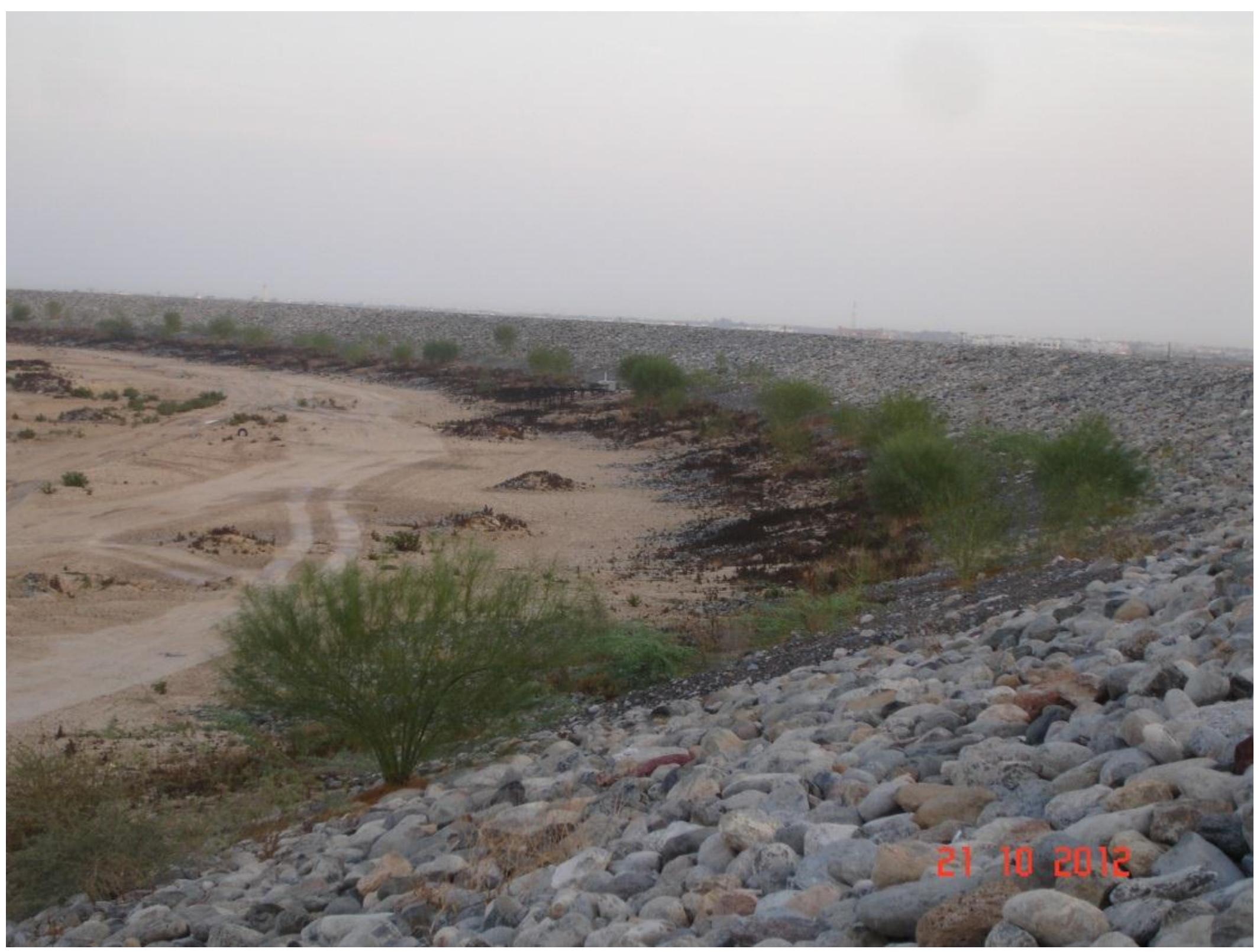


April 25, 2013: vegetation just before another extermination in Summer 2013. One day before a moderate rain.

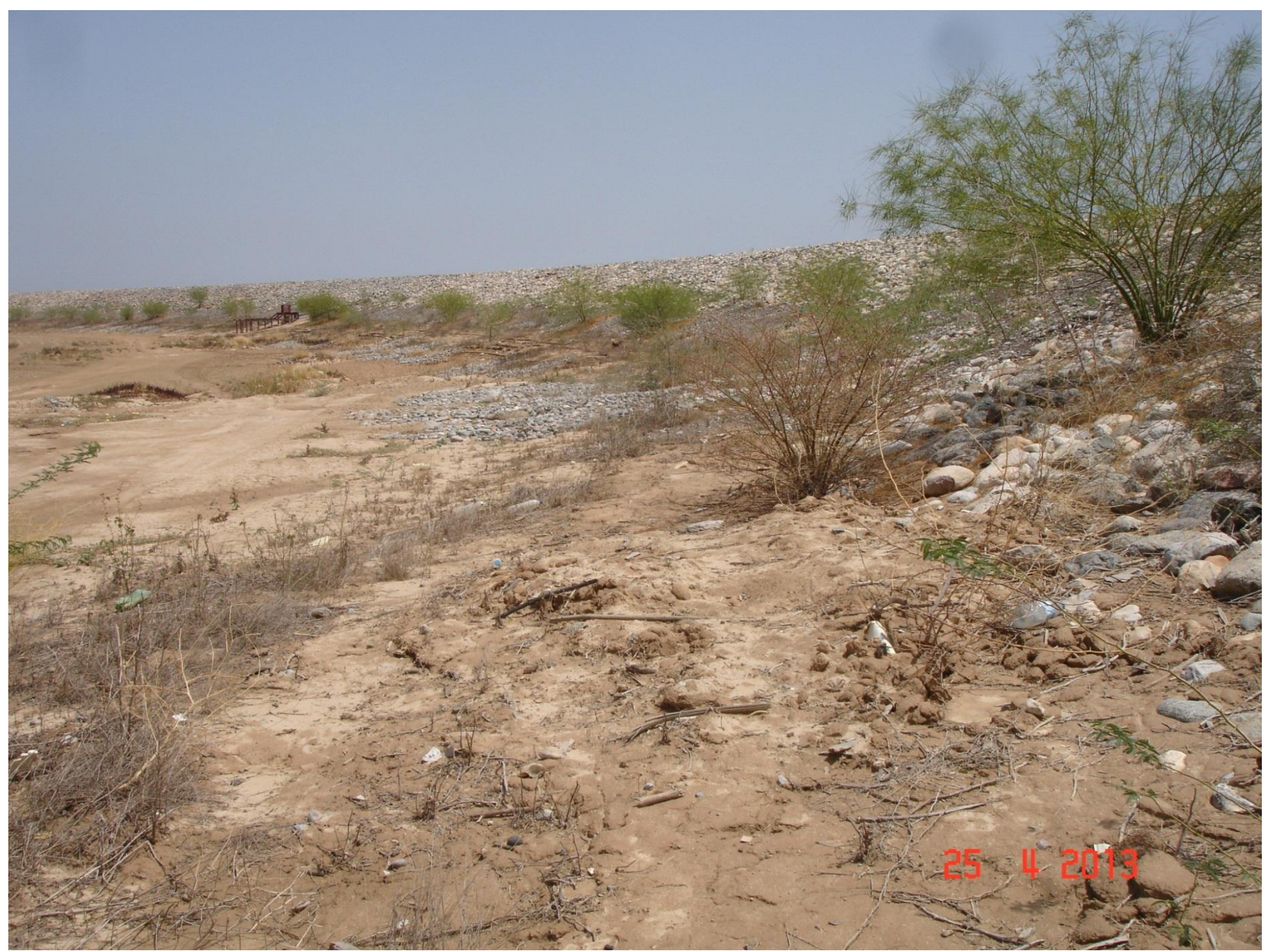


April 29, 2013: 3 days after a moderate rain, on the eave of a heavy rain (evening, April 29), water sampling from the reservoir

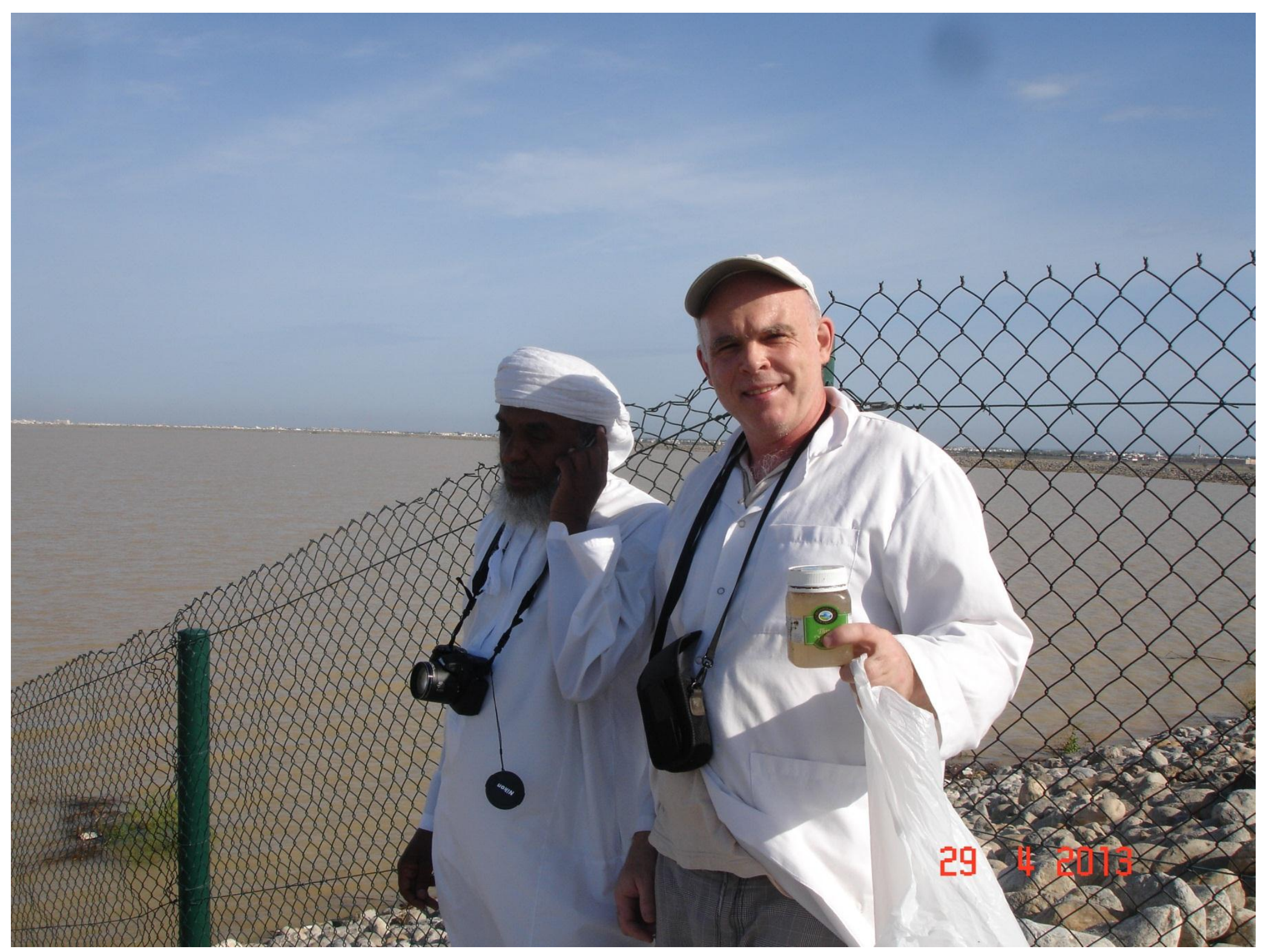




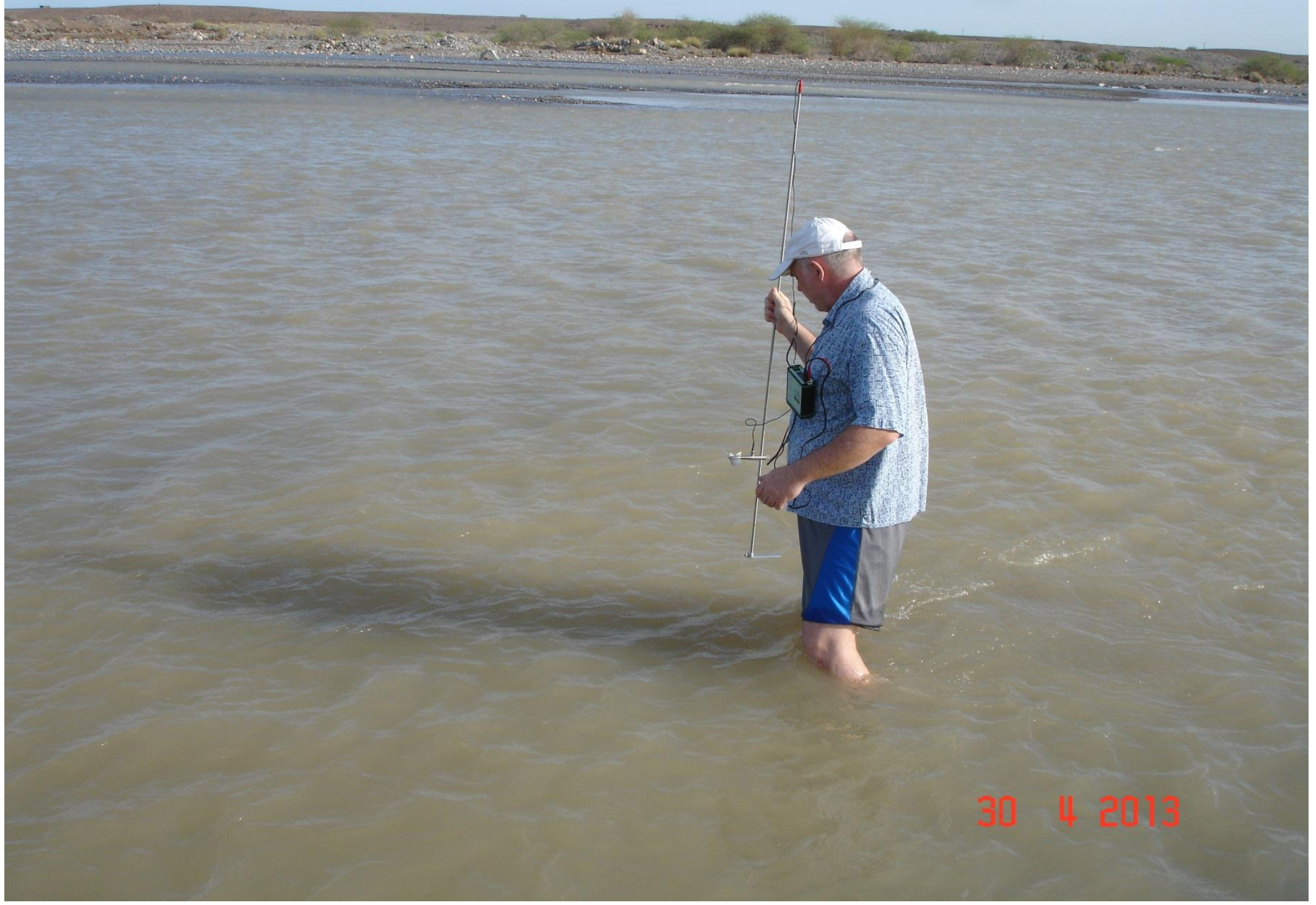


April 30, 2013: 1 day after a heavy rain, water depth measurements in the wadi feeding the reservoir

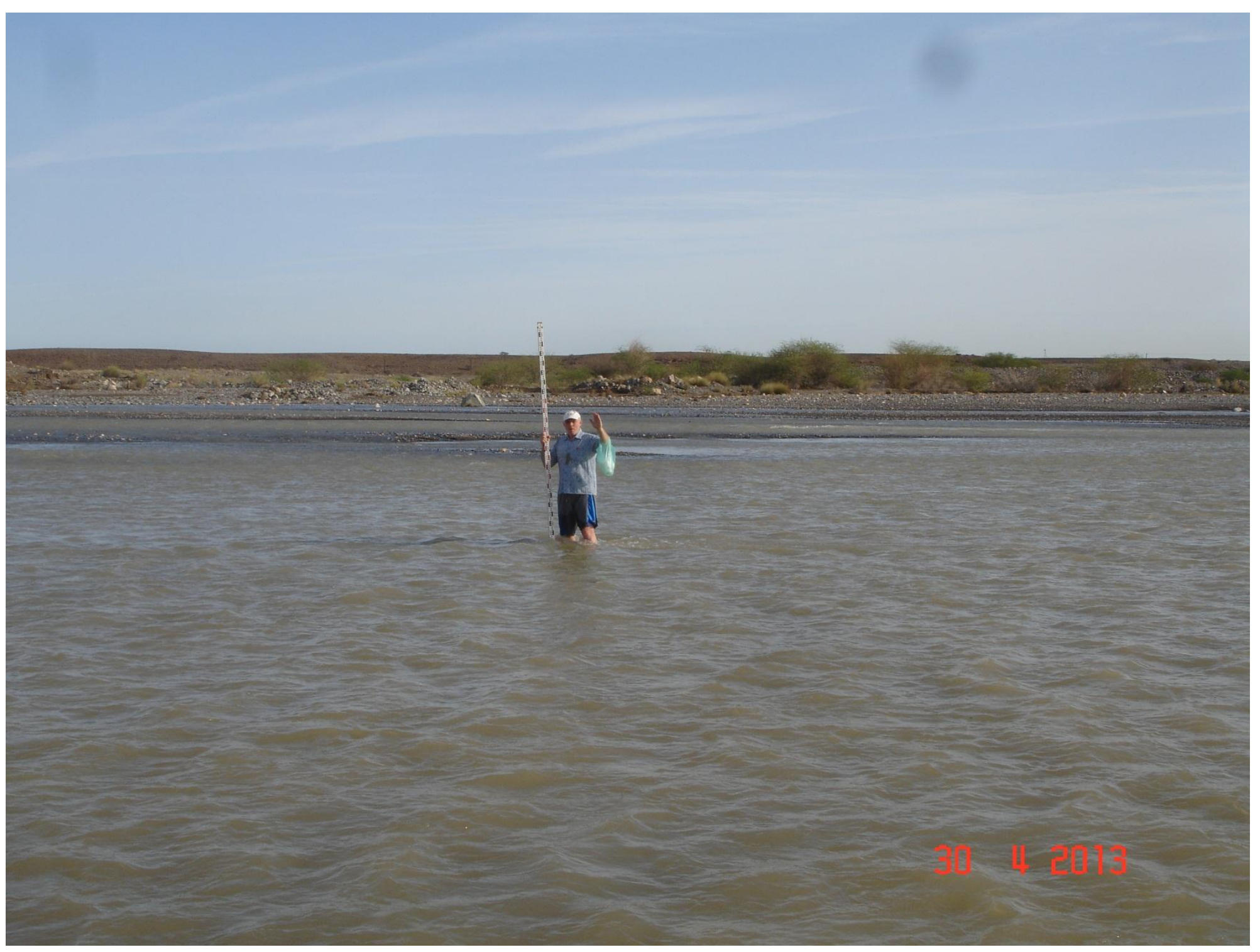


April 30, 2013: 1 day after a heavy rain, zone A, the reservoir is full

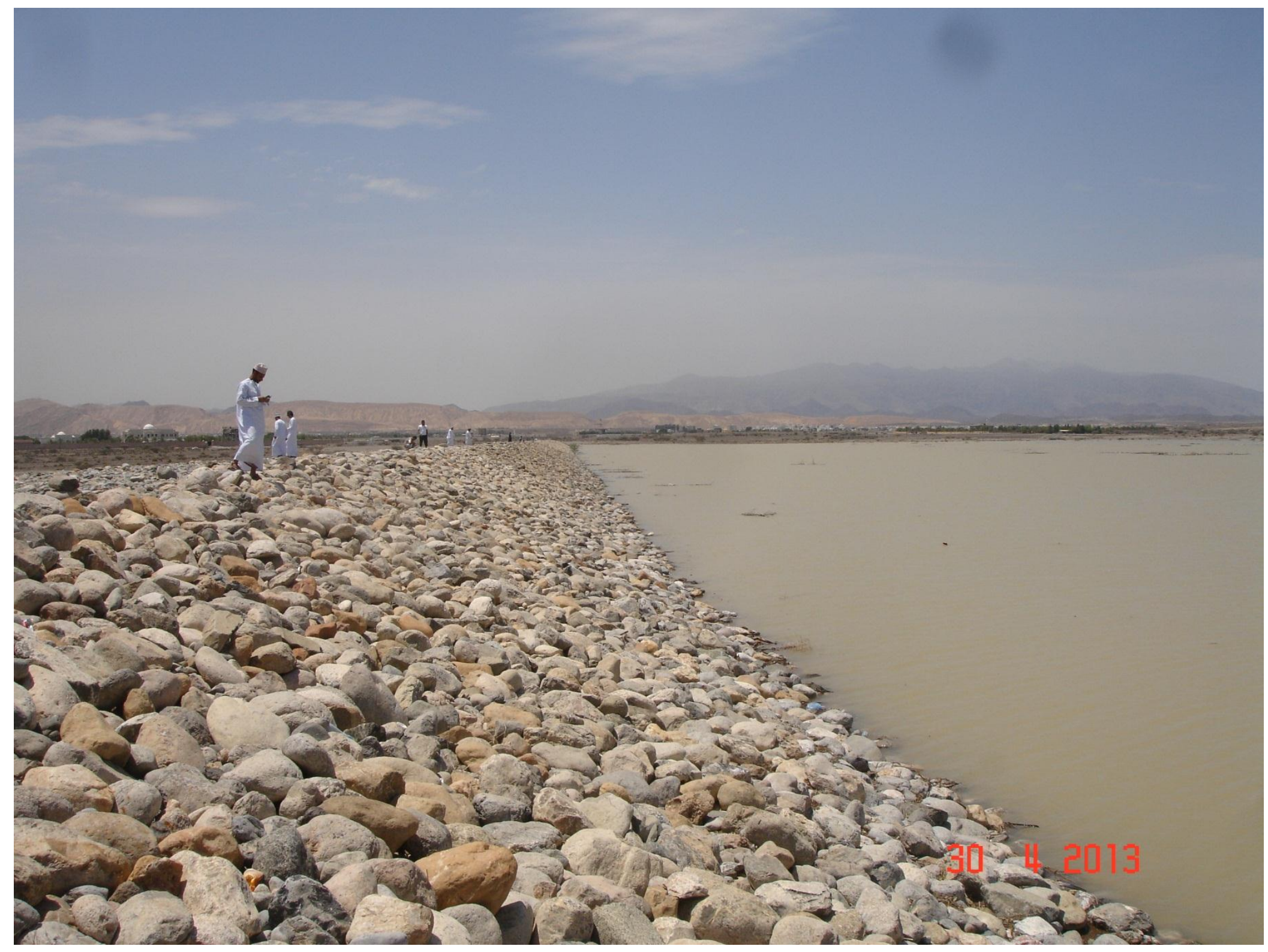




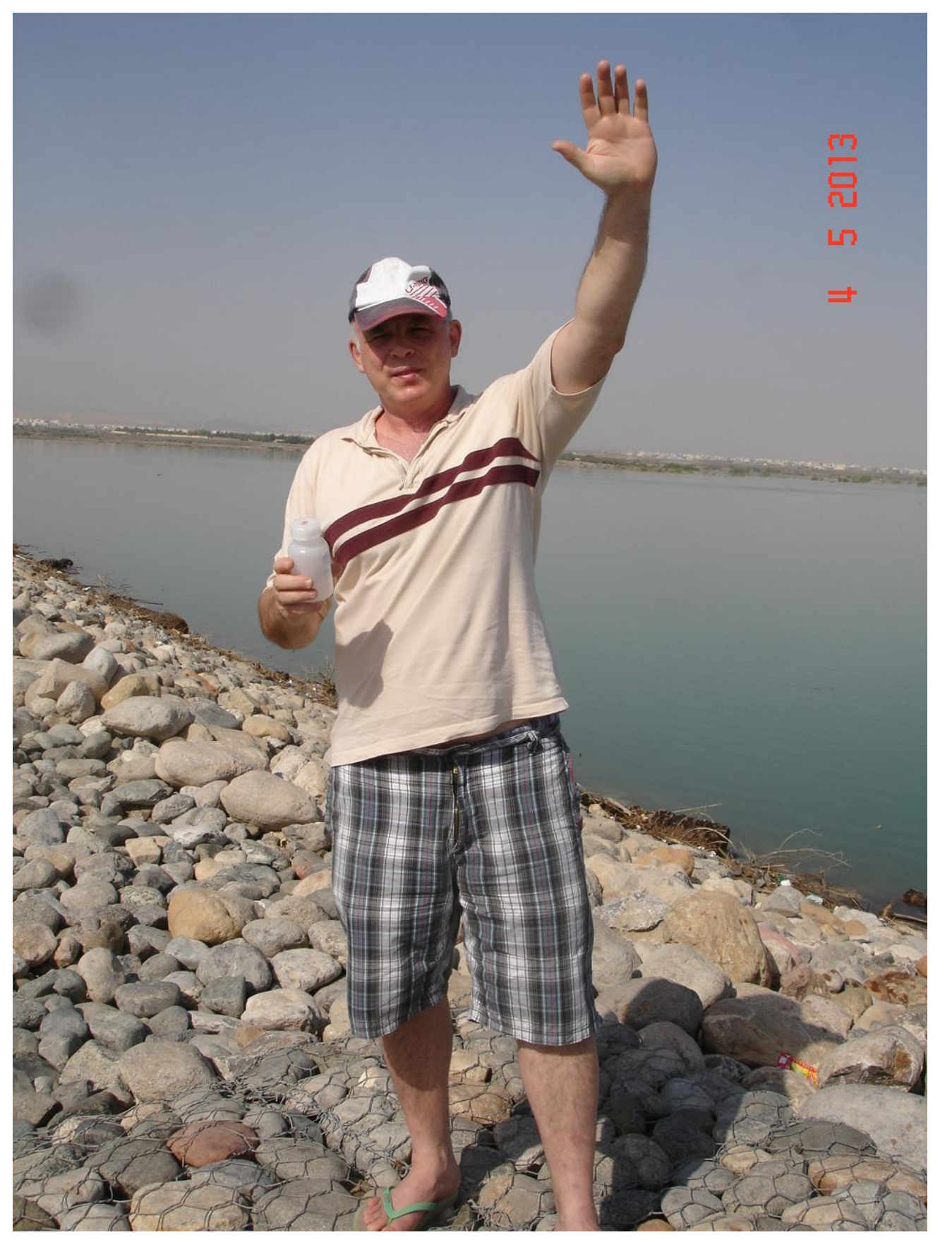

May 4, 6 days after a heavy rain, reservoir is full and the spillway section of the embankment was overtopped 
May 4, 2013, 6 days after a heavy rain, reservoir is full, culverts are open and keep discharging into the stilling basin

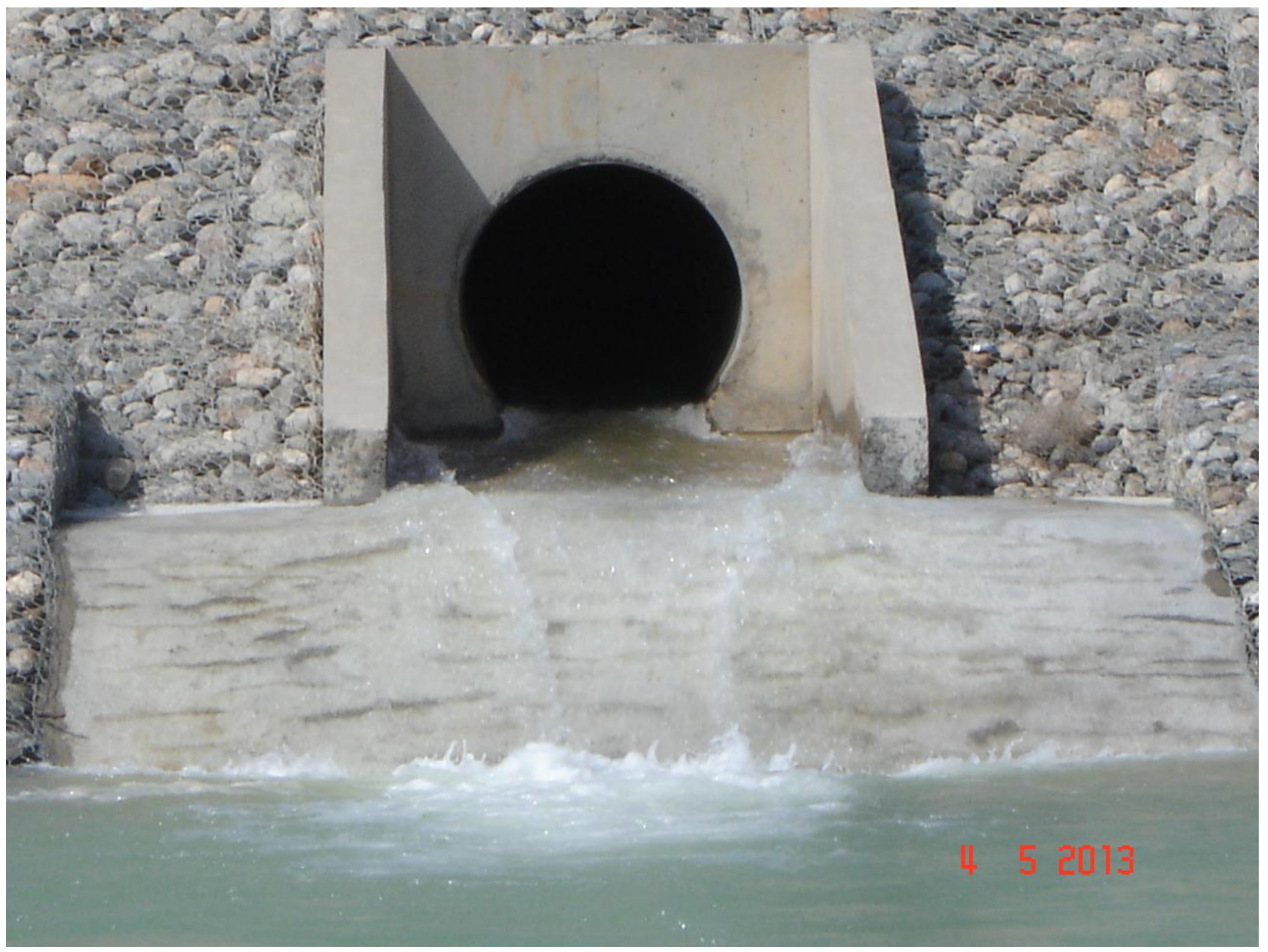


May 4, 2013, 6 days after a heavy rain, reservoir is full, the stilling basin is full of water 
May 24, 2013: spillway section (zone B) after a heavy rain on April 29

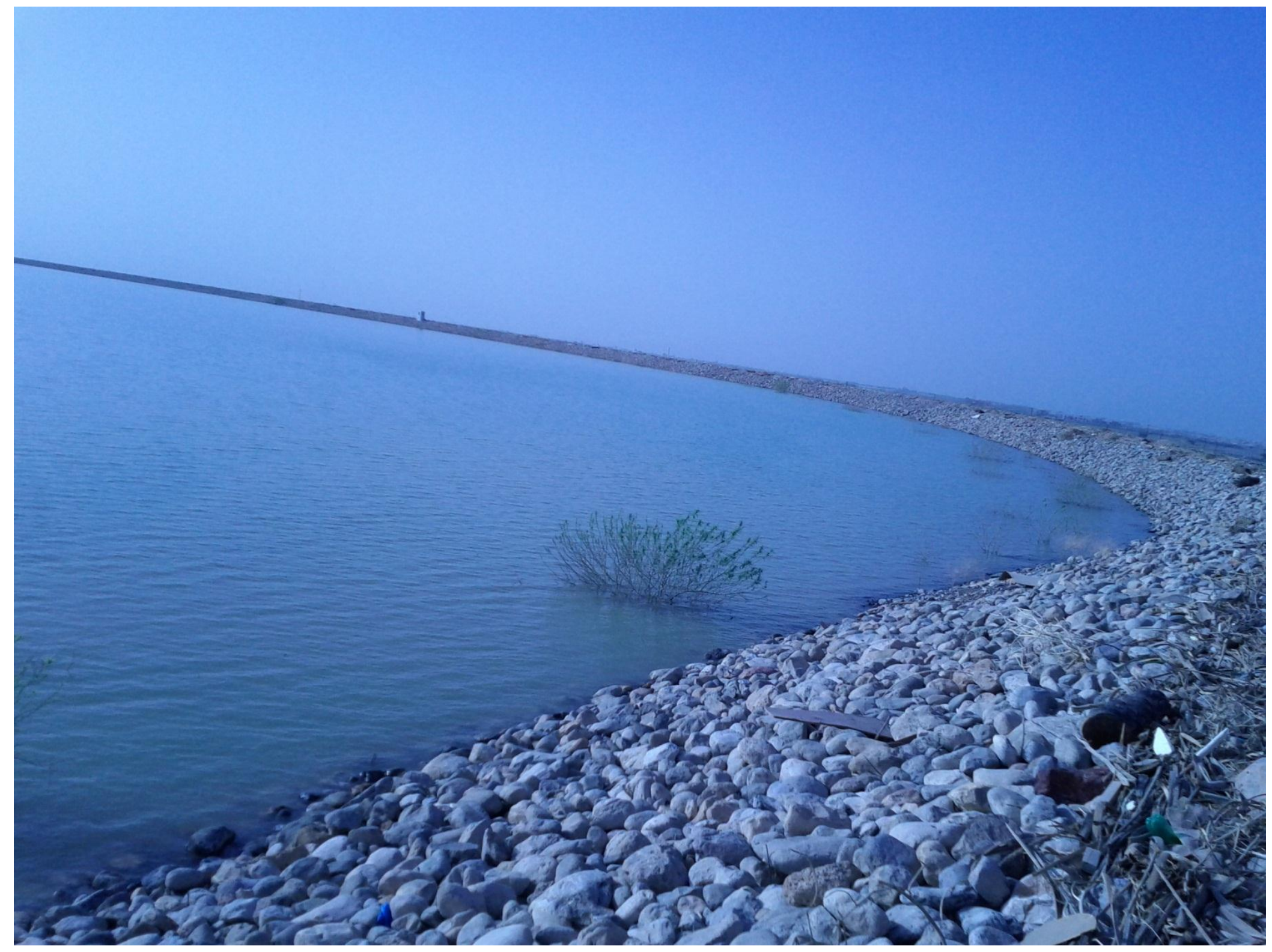


May 24, 2013: stilling basin 24 days after a heavy rain on April 29

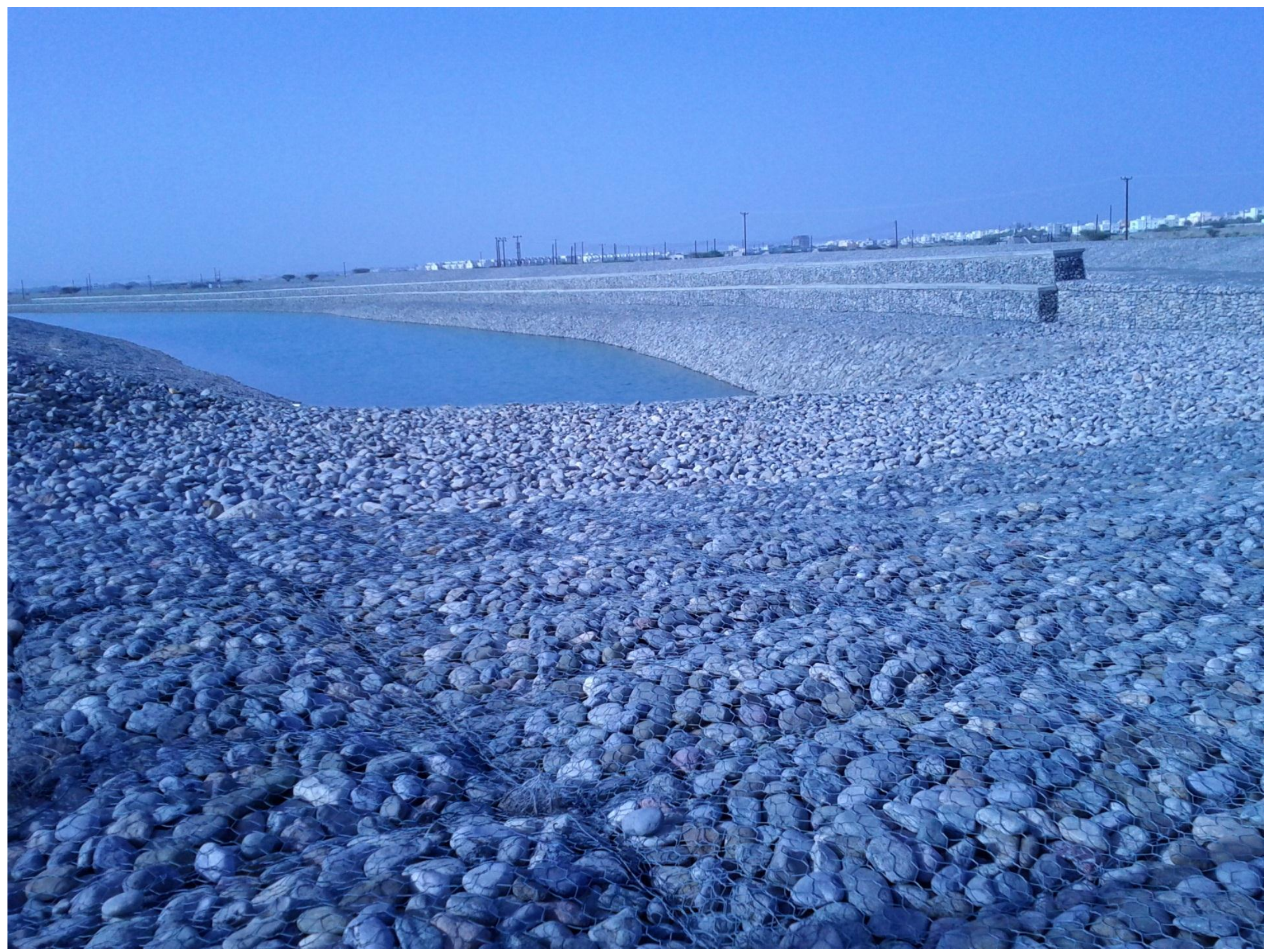


December 6, 2013: one week after a heavy rain. Stilling basin. Zone B

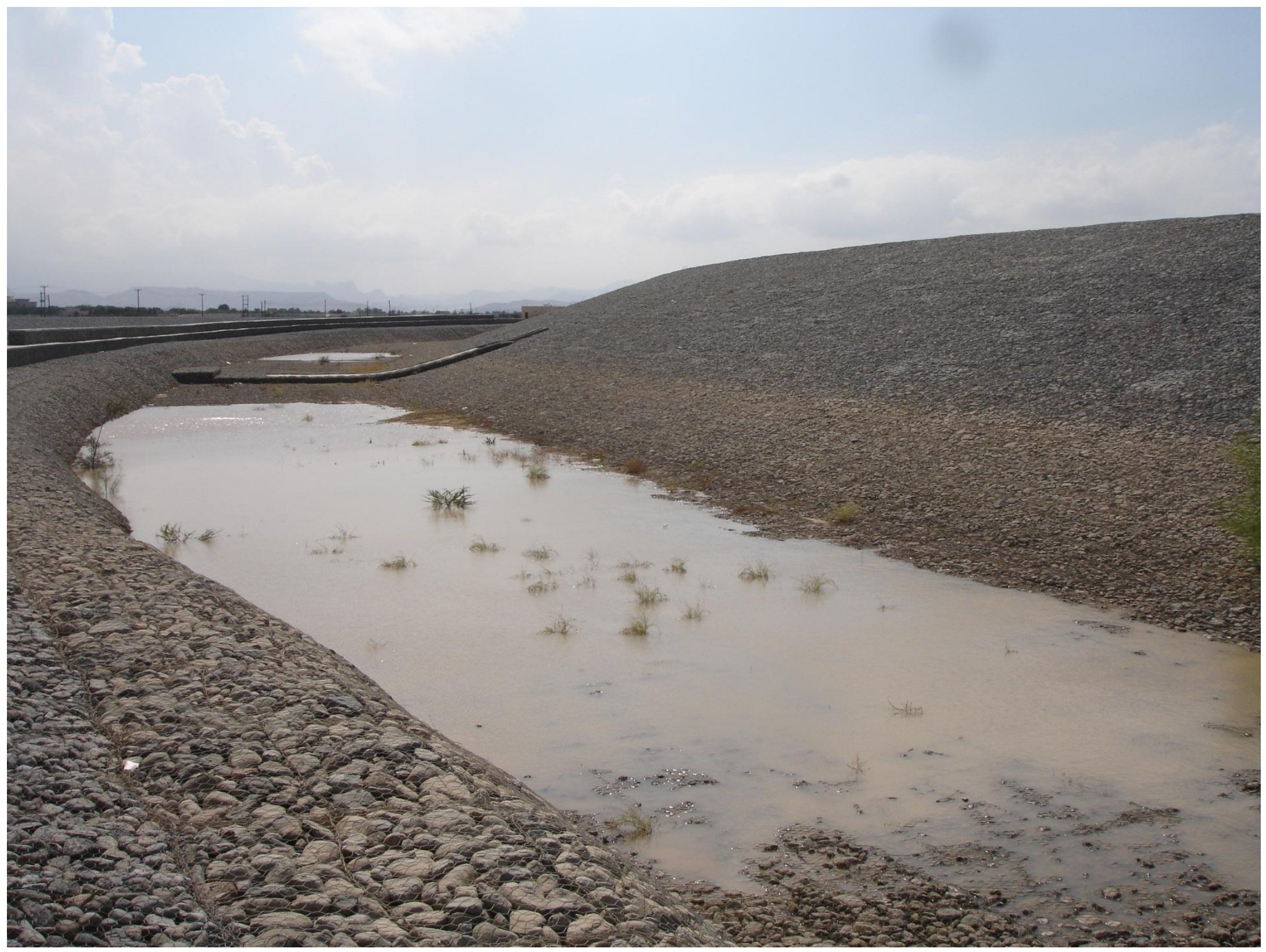


December 6, 2013: one week after a heavy rain. Spillway section (zone B) from the crest

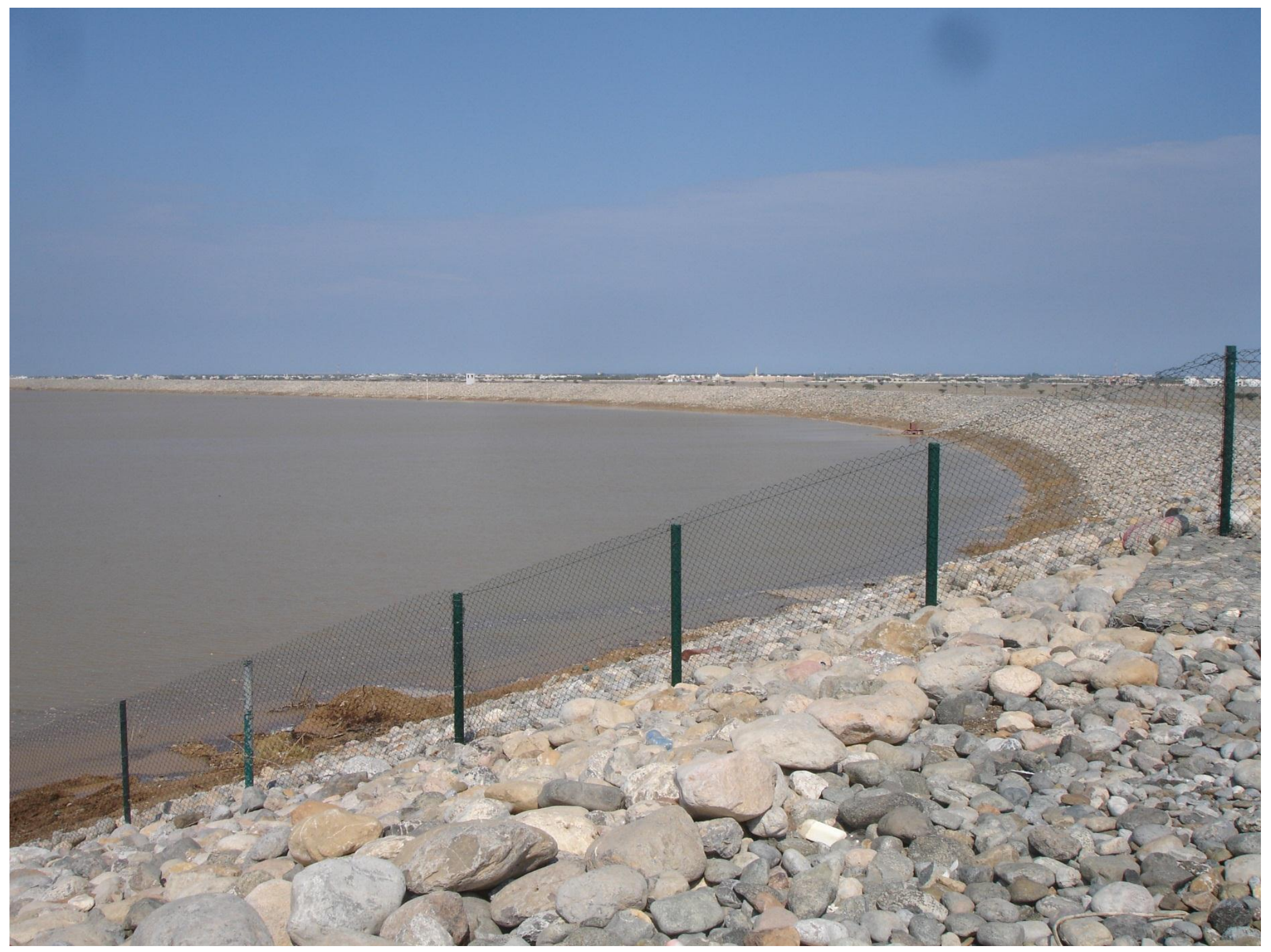


January 17, 2014: 2 day before the forthcoming moderate rain (woody plants exterminated in Summer 2013)

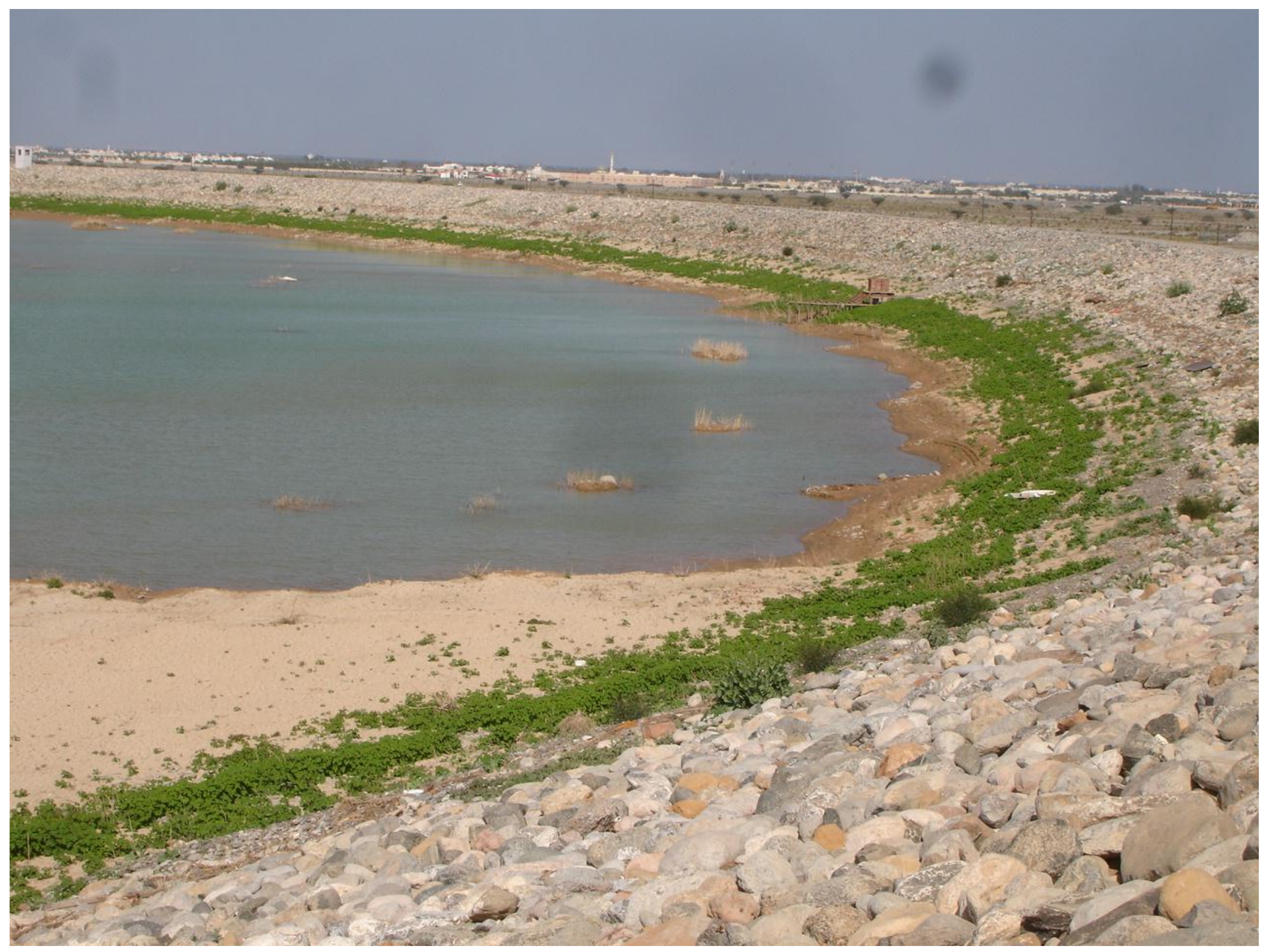


January 17, 2014: 1 day after the last moderate rain

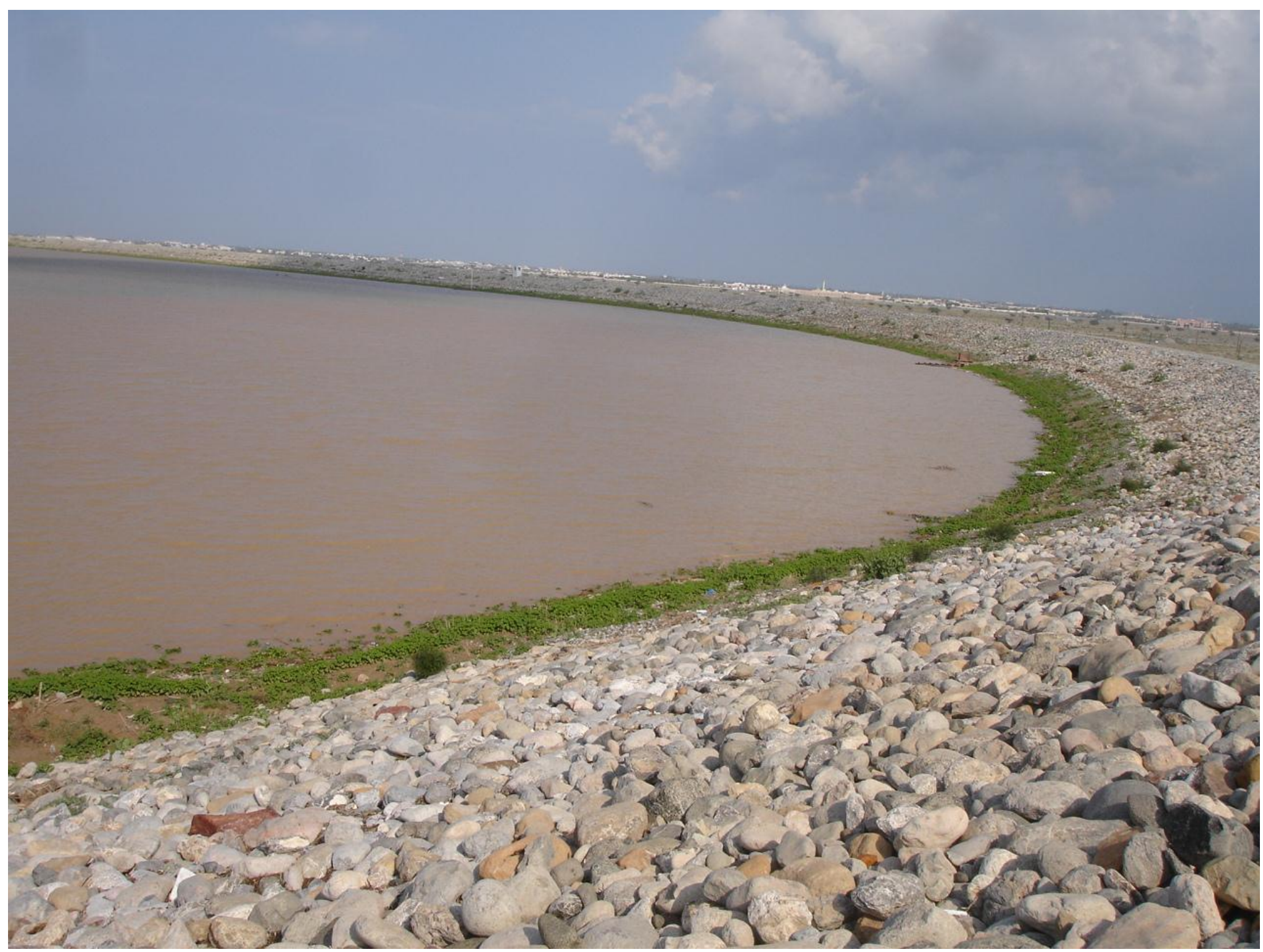


March 29, 2014: 2 days after the last mild rain, preceded by a moderate rain

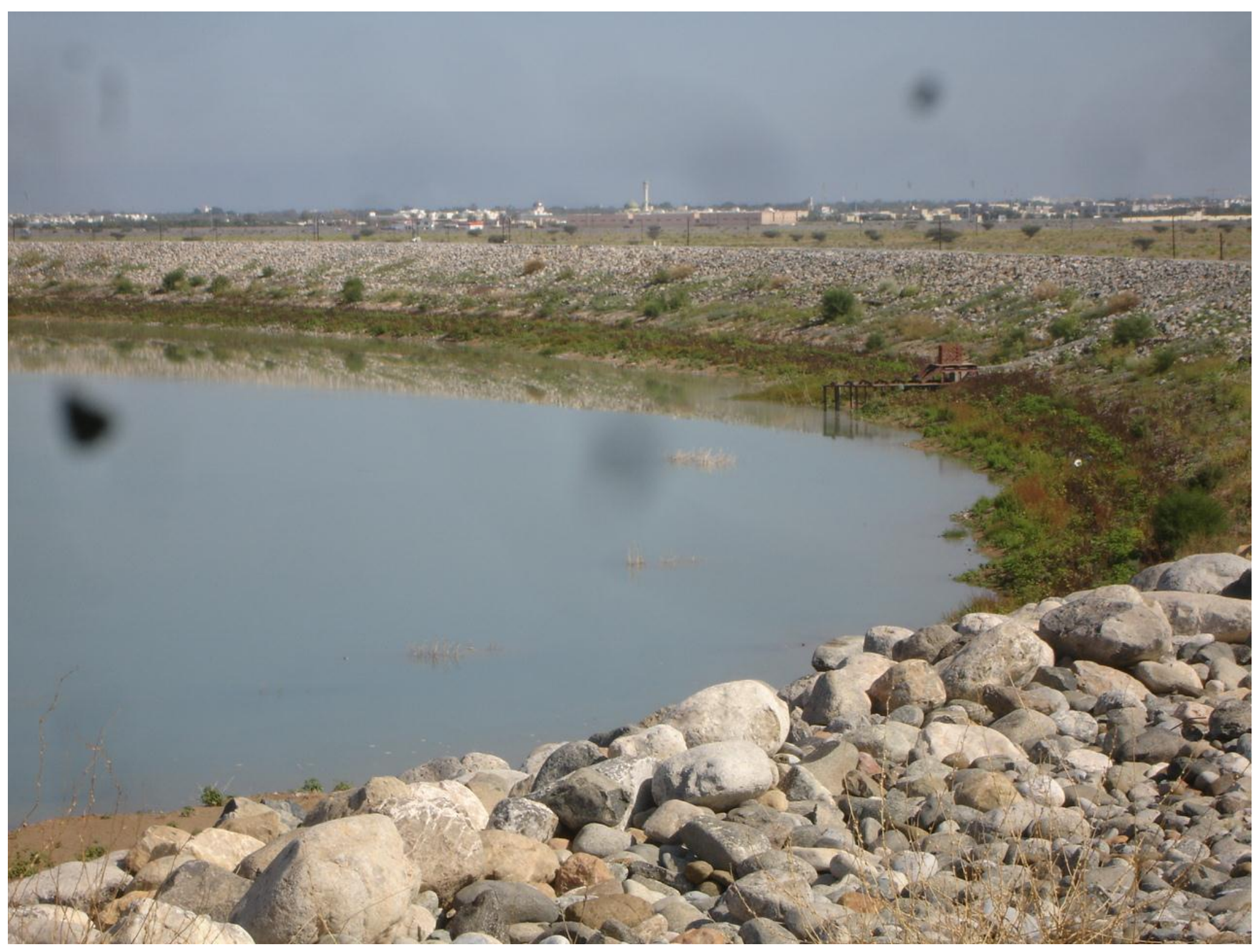


March 29, 2014: Christ-thorn (local name- sidr tree) in zone A of the dam, inside the reservoir. Fruiting season. Embankment on the background

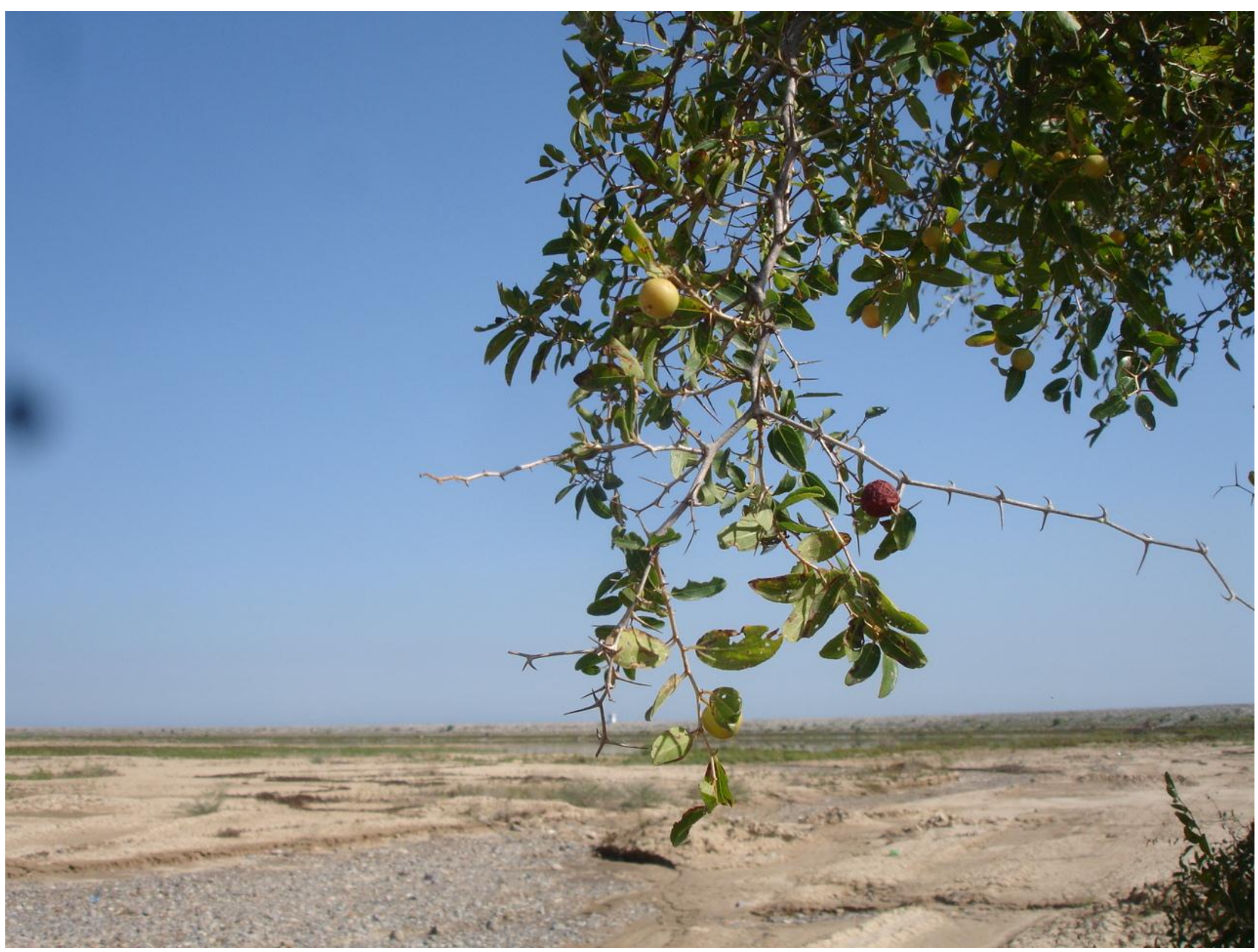


March 29, 2014: View from the dam crest after a mild rain

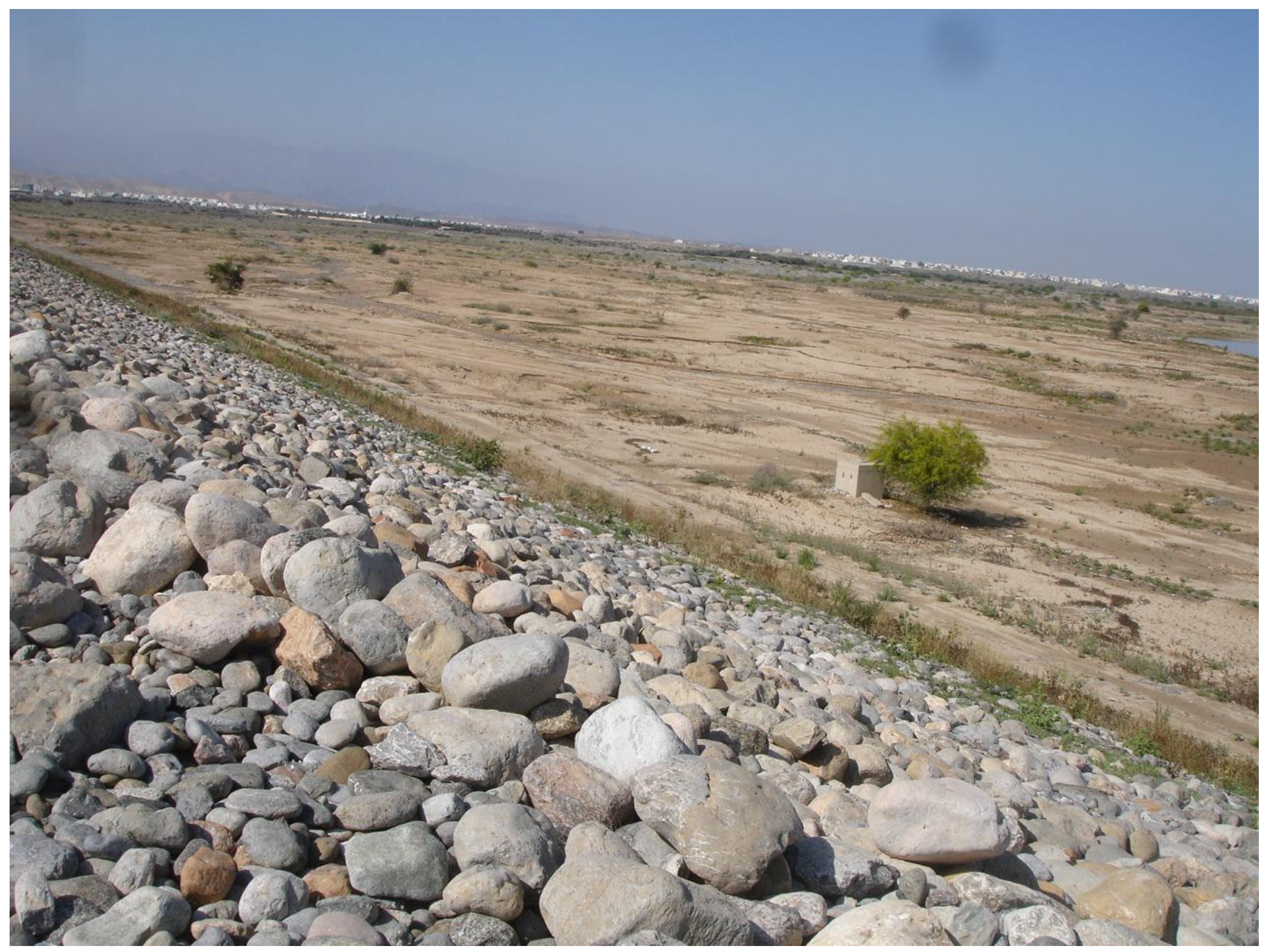

